\title{
LOS BENEFICIOS EMPRESARIALES EN ESPAÑA, 1880-1981. ESTIMACIÓN DE UN ÍNDICE ANUAL DEL EXCEDENTE DE LA GRAN EMPRESA *
}

XAVIER TAFUNELL

Universidad Pompeu Fabra

\section{RESUMEN}

En este artículo se presenta una serie anual de beneficios de la empresa en España para el período 1880-1981. El índice elaborado es altamente representativo de la gran empresa de nuestro país y constituye la primera estimación anual de renta empresarial que abarca un período muy largo. Los datos muestran que la evolución de beneficios se guió por tendencias de larga duración y por fluctuaciones de corto plazo. Ambos movimientos se acompasaron a los del producto total y del sector industrial. Los datos sugieren, asimismo, que las fluctuaciones de los beneficios estuvieron muy estrechamente correlacionadas con las de la inversión.

\section{ABSTRACT}

This article presents an serie of annual Spanish corporate's profits for the period 1880-1981. The index estimated represents very well spanish big firms, and it provides for the first time annual measurement on profits for a very long period. The data suggests that profits experienced long trends and short-term fluctuations. Both movements are related with whole economy and industrial dynamics. The data equally suggests that profits fluctuations were extremely correlated with investment fluctuations.

* Agradezco los comentarios críticos de tres evaluadores anónimos, así como los formulados por los participantes en un seminario realizado en el Departamento de Economía y Empresa de la Universidad Pompeu Fabra y en el II Encuentro de Historia Económica, celebrado en la Universidad Menéndez Pelayo en Valencia. Mención aparte merecen Albert Carreras y Lluís Castañeda, sin cuyo apoyo este trabajo no habría salido a la luz. 
El conocimiento sobre la evolución de la renta nacional de España durante el último siglo y medio ha mejorado sustancialmente en los últimos años. Todavía en 1985 Albert Carreras podía afirmar con acierto que nuestro país seguía sufriendo una agobiante escasez de series históricas del agregado macroeconómico fundamental. Pero con el propio ensayo en que formulaba tal aseveración contribuía de modo decisivo a convertirla en obsoleta ${ }^{1}$. Los investigadores de la economía española de los siglos XIX y $\mathrm{xx}$ somos deudores de su innovadora aportación, y así lo atestigua el hecho que probablemente haya sido la obra más citada en nuestra historiografía económica contemporánea en la última década. Más recientemente, los trabajos de Leandro Prados ${ }^{2}$ han ayudado mucho a ampliar el acervo de información sobre la renta nacional. Sus estimaciones han complementado y perfeccionado la elaboración de Carreras, al basar el cálculo de la renta en una movilización sistemática de las series de producción y precios construidas por los historiadores económicos, y aproximarse al mismo por el lado del producto, en lugar del lado del gasto adoptado por Carreras. Así pues, gracias a los trabajos de ambos, disponemos de series largas de la renta nacional -dan comienzo, como es bien sabido, en 1849 y 1850 , respectivamente, y enlazan en 1958 con la serie de la Contabilidad Nacional que elabora el INE - merecedoras de un alto grado de confianza. Sin embargo, está fuera de discusión que siguen existiendo significativos márgenes de mejora en la cuantificación retrospectiva de la renta nacional española, aunque sólo sea por la circunstancia que aún está por hacer una estimación de la misma por el lado del ingreso. No es una cuestión baladí, ya que más allá del refinamiento estadístico está el hecho que los grandes avatares de la historia contemporánea de España han estado ligados a cambios en la distribución de la renta. Difícilmente podemos aspirar a formular esquemas interpretativos «indiscutibles» sobre la dinámica de la economía española sin contar con series históricas de los principales componentes del ingreso nacional.

Con toda seguridad, esta ausencia es debida a las enormes dificultades que surgen al tratar de estimar la renta a través del enfoque ingreso para un país como España, que se caracteriza por no contar con estadísticas fiscales suficientes y creíbles sobre las rentas percibidas por las economías familiares y las empresas ${ }^{3}$. El desprestigio de la fuentes fiscales, a estos

1 Carreras (1985).

2 Prados (1993 y 1995).

${ }^{3}$ Carreras, en el trabajo citado, menciona este problema, al cual atribuye que las 
fines, entre los historiadores económicos españoles ha sido tan grande que éstos han tendido a desechar los datos publicados sobre ingresos de los agentes económicos que irrogan obligaciones tributarias ${ }^{4}$. En concreto, los resultados de las empresas publicados han sido tradicionalmente considerados no veraces. Desgraciadamente, está tan arraigada en la opinión pública la convicción de que los empresarios han cometido un abultado y sistemático fraude fiscal que ha llevado a los historiadores económicos a considerar que las cuentas de pérdidas y ganancias de las sociedades han sido, hasta fechas muy recientes, falseadas al extremo que no son apropiadas para el análisis histórico-económico. Pero eso está por demostrar. En este ensayo espero probar que tal idea preconcebida carece de fundamento, construyendo a partir de estos materiales una serie de beneficios cuya trayectoria parece verosímil y congruente con la que siguieron otros agregados macroeconómicos. Si así fuese, la serie que presento aportaría una de las piezas para la estimación de la renta nacional por el lado del ingreso.

Desde luego, hay otras razones de peso que justifican, a mi juicio, gastar abundantes energías investigadoras en la elaboración de una serie histórica de los resultados de la empresa española. Bastará señalar que el conocimiento de su evolución tiene gran importancia en el análisis de los ciclos económicos, puesto que en las economías capitalistas fluctúan en estrecha correspondencia con el desarrollo de éstos ${ }^{5}$. En segundo lugar, es inconcebible que podamos avanzar grandemente en el terreno de la historia de la empresa en la España contemporánea -empeño al que actualmente están entregados numerosos historiadores económicos de este país, entre los que me incluyo- sin disponer, entre otras variables básicas, del marco de referencia de los beneficios y las rentabilidades logradas por la misma.

Un ejercicio de reconstrucción estadística de los beneficios empresariales como el que aquí se da a conocer apenas tiene precedentes

estimaciones de la renta realizadas en nuestro país se basen en el cálculo del producto. En lo que se refiere, concretamente, a las estadísticas del impuesto sobre los beneficios de las sociedades - incluido dentro de lo que se denominaba Contribución de Utilidades de la Riqueza Mobiliaria hasta la reforma tributaria de 1957- las indagaciones realizadas hasta ahora por los investigadores evidencian un fraude fiscal abultado con respecto a... ilos beneficios declarados por las propias sociedades que aparecían publicados en la prensa financiera especializada! Véase Betrán (1994). Por este motivo y por otros no irrelevantes - como el tremendo desorden de dichas estadísticas- he renunciado a utilizar esta fuente para la elaboración cuantitativa que ahora presento.

${ }^{4}$ En una obra muy reciente, el mayor experto de nuestro sistema tributario reafirma contundentemente este severo diagnóstico, véase Comín (1996), pp. 94-115.

5 Véase Zarnowitz (1992). 
en España ${ }^{6}$. Por ello, mi elaboración tiene un carácter preliminar y adolece de algunas limitaciones que podrían ser superadas en ulteriores cuantificaciones. Es oportuno señalar, antes de nada, las principales características e insuficiencias de mi estimación. Son las siguientes: 1) constituye la primera $-y$, en consecuencia, por ahora la única- serie de renta empresarial agregada auténticamente larga en términos históricos. Tratándose de una serie secular -en un sentido casi exactamente literal: abarca ciento un años-, pueden fundamentarse análisis de la evolución a largo plazo; 2) tiene un carácter anual, lo que permite apreciar las fluctuaciones a corto plazo; 3) la estimación no pretende ser representativa del conjunto de la empresa española, sino tan sólo de la gran empresa - cualquiera que sea la variable a la que se refiera-, como reza el propio título del artículo. Hay, pues, otros índices posibles de beneficios, relativos a las PYMES, cuya trayectoria acaso presente discrepancias con la del índice que yo he calculado. Con todo, la cobertura de mi estimación es bastante elevada al tener las empresas cuyos resultados integran el agregado un peso considerable en el conjunto de las empresas existentes; 4) mi serie finaliza en 1981. He renunciado a llevarla hasta la actualidad porque esto hubiera implicado enlazarla o competir con las series de la Central de Balances, elaborada por el Banco de España, y la del Impuesto de Sociedades, producida por el Instituto de Estudios Fiscales, que tienen una calidad incomparablemente mayor ${ }^{7}$, y 5) la magnitud estimada, por imperativos metodológicos, comprende el consumo de capital —real o presunto-. Esto conlleva un serio inconveniente a la hora de utilizar el índice para evaluar la distribución factorial de la renta, que, inevitablemente, deberá subsanarse en el futuro cuantificando y deduciendo la amortización del capital.

Este ensayo consta de cinco partes. La primera está dedicada a exponer la metodología del cálculo del agregado, así como, de forma sumaria, los problemas que plantean los datos. Puesto que éstos han levantado tantas sospechas forzoso es que prestemos bastante atención a esta cuestión. En la segunda parte se comparan los resultados obtenidos con los de las (escasas) estimaciones precedentes; en la tercera hago una presentación rápida de la serie elaborada; en el cuarto apartado contrasto la evolución de la misma con la de las macromagnitudes básicas (producción industrial, inversión, producto total), examinando de forma algo más detenida la que,

\footnotetext{
6 Véase infra, apartado 2.

${ }^{7}$ Sobre las estadísticas recientes, véanse los diversos artículos dedicados al tema en el número 299 de la revista Economia Industrial, particularmente los de Gómez, Melis y Truyols (1994) y de Ortega (1994).
} 
sin duda alguna, es la comparación más sugestiva: beneficios e inversión. Se cierra el artículo con una recapitulación de sus aspectos más relevantes, a modo de conclusión.

\section{LOS DATOS Y EL MÉTODO}

La validez y fiabilidad de cualquier estimación de una serie histórica de un agregado macroeconómico viene dada por tres factores: el grado de cobertura de los componentes de la misma con respecto a la macromagnitud calculada, el sistema de ponderación de las series elementales que forman el índice, y, por supuesto, la calidad de la información de base con la que se han elaborado estas series. Abordaré el primer y el tercer elemento enunciados, por este orden, dejando para el final el segundo, por cuanto lleva envuelto el procedimiento de cálculo ${ }^{8}$.

Como he señalado en la introducción, no pretendo haber construido una serie representativa de los resultados de la globalidad de la empresa en España ${ }^{9}$. Por el contrario, en los cómputos sólo han tenido cabida las sociedades anónimas de grandes dimensiones, bien sea en relación a las empresas del sector, o bien en términos del conjunto del tejido empresarial ${ }^{10}$. Esta opción ha venido sencillamente impuesta por la disponibilidad de información. Las fuentes consultadas -esencialmente, el Anuario(s) Financiero(s) y de Sociedades Anónimas de España, en adelante AFSAE $^{11}$ - no suministran ningún dato sobre las empresas de reducido tamaño, o, para ser más exactos, las empresas con un régimen jurídico distinto

${ }^{8}$ Para mayores detalles, véase Tafunell (1996).

9 Nótese que digo en España, y no española, por cuanto el agregado calculado incluye companías extranjeras que han desarrollado su actividad en nuestro país, y en cambio no toma en cuenta las firmas españolas que han operado allende nuestras fronteras.

${ }^{10}$ Los criterios de selección han sido los siguientes. He retenido las cifras de resultados de las sociedades que aparecen en los AFSAE cuyo capital desembolsado cumple alguno de estos dos requisitos: representar al menos el 1 por 100 del de su sector (según la clasificatoria sectorial de los propios AFSAE) o bien el 1 por 1.000 del capital desembolsado por la totalidad de las sociedades censadas en alguno de los años 1920, 1930, 1940, 1950, 1960 y 1975. Cuando una empresa supera el umbral en uno o más años consecutivos y no en los restantes, he recogido información, o, en su defecto, he estimado los beneficios de los cinco años anteriores y posteriores al primer y último de los cortes temporales mencionados en que sobrepasa el umbral.

${ }^{11} \mathrm{He}$ empleado como fuente primordial el mencionado Anuario Financiero $y$ de Sociedades Anónimas de España. Siempre que me ha sido posible he contrastado la información con el Anuario Financiero de Bilbao, editado por Guillermo Ibáñez, de Bilbao. Sobre lạs características y potencialidades de estas publicaciones, véase Tafunell (1989). 
al de las sociedades anónimas. En realidad, las fuentes ni siquiera ofrecen sistemáticamente datos válidos de los resultados de todas las sociedades anónimas importantes. Tanto es así que dos de las principales debilidades de mi cuantificación derivan de: 1) la relativa abundancia de lagunas en las series de las empresas seleccionadas, y 2) la escasez de series elementales en determinados periodos. Por ello, es pertinente que veamos cuál es el grado de cobertura de las empresas que he seleccionado con respecto a la totalidad de las sociedades anónimas. El cuadro 1 nos da la respuesta.

\section{CUADRO 1}

Grado de cobertura del indice total y de algunos indices sectoriales

\begin{tabular}{|c|c|c|c|c|c|}
\hline Sector & 1920 & 1930 & 1950 & 1960 & 1975 \\
\hline 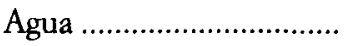 & 74,9 & 43,1 & 52,8 & 61,8 & 68,6 \\
\hline 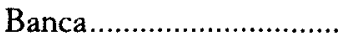 & 64,8 & 76,8 & 72,4 & 77,2 & 76,6 \\
\hline 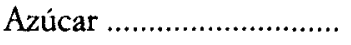 & 59,7 & 49,9 & 67,3 & 66,1 & 66,2 \\
\hline Construcción naval......... & 66,6 & 67,5 & 85,8 & 71,9 & 69,5 \\
\hline Electricidad .................... & 13,7 & 33,6 & 50,3 & 79,7 & -1 \\
\hline Inmobiliario ................... & 一 & - & 13,1 & 21,9 & 18,9 \\
\hline Maquinaria ...................... & 26,0 & 29,0 & 24,5 & 21,5 & 14,5 \\
\hline Minería .......................... & 23,2 & 28,2 & 30,5 & 10,3 & 25,6 \\
\hline Monopolios ................... & 100,0 & 94,9 & 83,6 & 90,9 & 99,8 \\
\hline Navegación.................... & 20,6 & 28,8 & 62,4 & 63,1 & 21,5 \\
\hline Petróleo ........................... & - & 一 & 26,3 & 83,1 & 47,1 \\
\hline 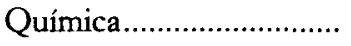 & 57,2 & 35,8 & 26,7 & 36,1 & 30,5 \\
\hline 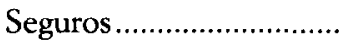 & 24,0 & 19,8 & 17,3 & 16,1 & 23,1 \\
\hline 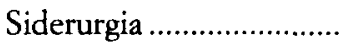 & 78,4 & 80,1 & 47,4 & 23,9 & 75,8 \\
\hline Textil .................................. & 13,0 & 9,8 & 11,7 & 7,4 & 4,8 \\
\hline TOTAL .................... & 43,0 & 45,1 & 48,2 & 51,3 & 46,9 \\
\hline
\end{tabular}

${ }^{1}$ No ha sido posible calcularlo, debido a que el total sectorial del AFSAE es incorrecto.

A mi entender, la tasa de cobertura -medida por los capitales desembolsados- es, en términos globales, elevada. Está cercana, en promedio, al 50 por 100 , se mantiene muy estable y no decae en las décadas finales, cuando las filas de las sociedades anónimas se ven engrosadas por un aluvión de empresas de pequeña dimensión constituidas o reconstituidas en forma de sociedades anónimas. A la vista de estas cifras me atrevería a afirmar que la gran empresa está realmente muy bien representada en 
mi estimación, cuando menos de 1920 en adelante. Cierto es que, si descendemos al detalle sectorial, la cobertura se torna muy variada, $y$, en ocasiones, variable a lo largo del tiempo. Esto debe prevenirnos contra la tentación de una excesiva descomposición del índice.

Ahora bien, en la prueba que acabo de realizar he dejado de lado las primeras décadas del período abarcado en este estudio, por la sencilla razón que no contamos para esta época con un cuadro estadístico de los capitales de las sociedades anónimas. Ello encubre la más que probable baja representatividad de la serie en los años que van de 1880 a 1900 , y, en menor medida, hasta 1910. Porque, en efecto, el número de series elementales que integran el agregado se hace más y más menguado a medida que nos remontamos en el tiempo. La escasez adquiere tintes alarmantes en cuanto retrocedemos más allá de 1910, y deviene agobiante para el período anterior a 1900. El cuadro 2 da noticia puntual de esta carestía. A la vista de los valores de las primeras fechas, el lector ha de acoger con cautela mi estimación para las dos últimas décadas del siglo xIx. Aquí hay, claramente, campo abierto para revisiones a fondo de mis cifras en ulteriores estimaciones. También existe un amplio margen de mejora en el segundo período en que se adelgaza dramáticamente la masa de series, en los años 1935-1939 ${ }^{12}$.

La evolución de la serie calculada durante los años noventa (véase anexo 1 y gráfico 1) - particularmente, entre 1894 y 1899, cuando da un enorme salto, no igualado en ningún otro lustro- exige ahondar en las interioridades de mi estimación en esta etapa. Un repaso de las series individuales de resultados pone en claro que hasta 1910, y, sobre todo, antes de 1900 , la trayectoria de mi serie agregada depende en extremo de los resultados de una decena de sociedades gigantescas, a saber: las compañías ferroviarias Norte, MZA y Andaluces, el Banco de España y el Hipotecario, las compañías minero-metalúrgicas Río Tinto, Asturiana de Minas, Peñarroya y Tharsis, y el monopolio industrial Arrendataria de Tabacos. Los resultados conjuntos de estas empresas suponen prácticamente el 80 por 100 del total entre 1880 y 1900 . En consonancia con tan enorme peso, la curva de la magnitud que he calculado es un calco de la que se obtiene sumando los beneficios de estas diez empresas, como salta a la vista en el gráfico 2. Éste pone al descubierto algo más:

${ }_{12}$ El detalle anual del cuadro -en Tafunell (1996), p. 8- muestra con claridad el brutal impacto que tuvo la Guerra Civil sobre la publicación de las cuentas de resultados y balances de situación de las empresas. Las 140 series del año 1934 se reducen a 45 en 1937 y a 52 en 1938. 


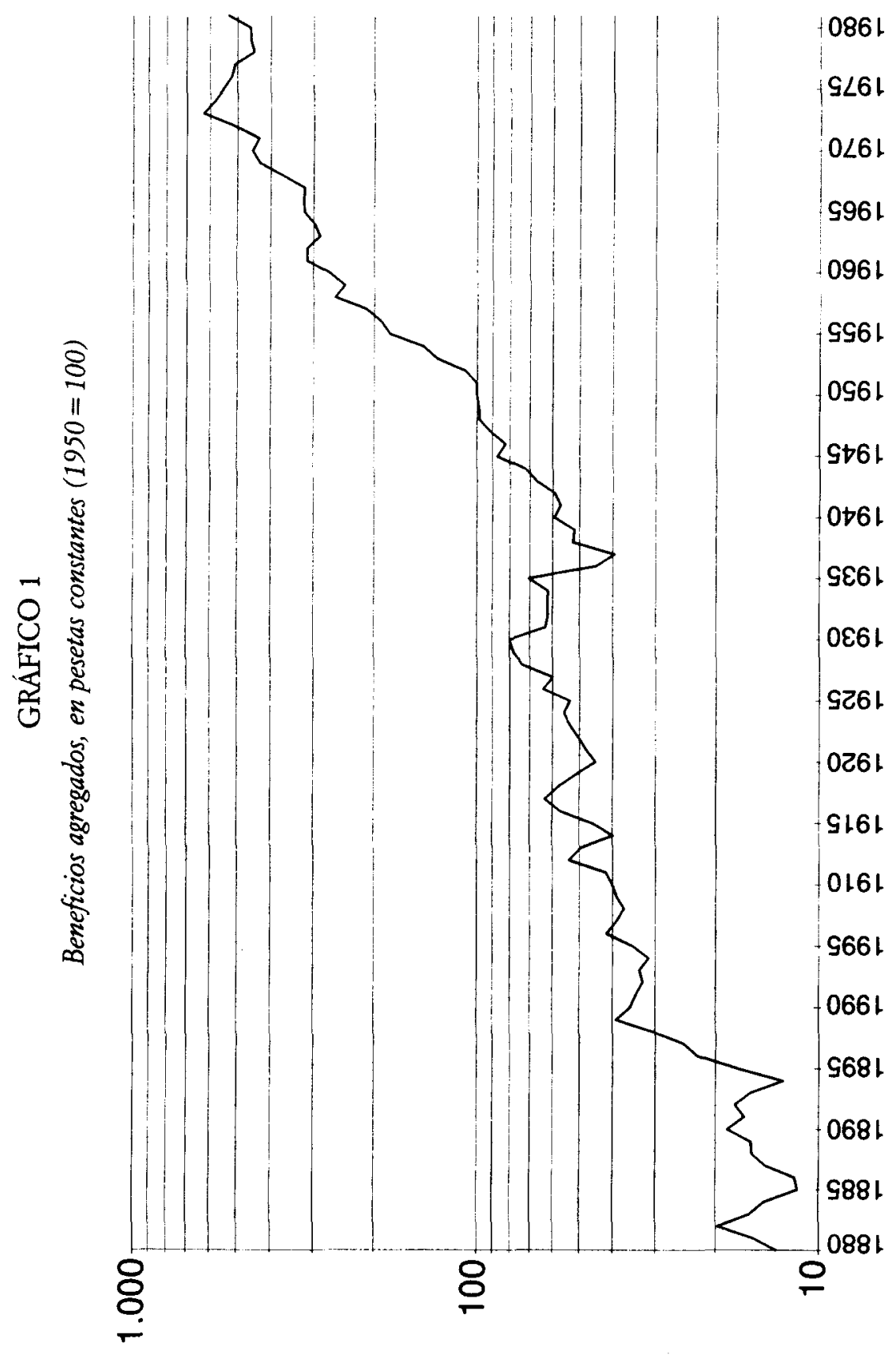




\section{GRÁFICO 2}

Beneficios de las principales sociedades y beneficios agregados, en miles de pesetas corrientes

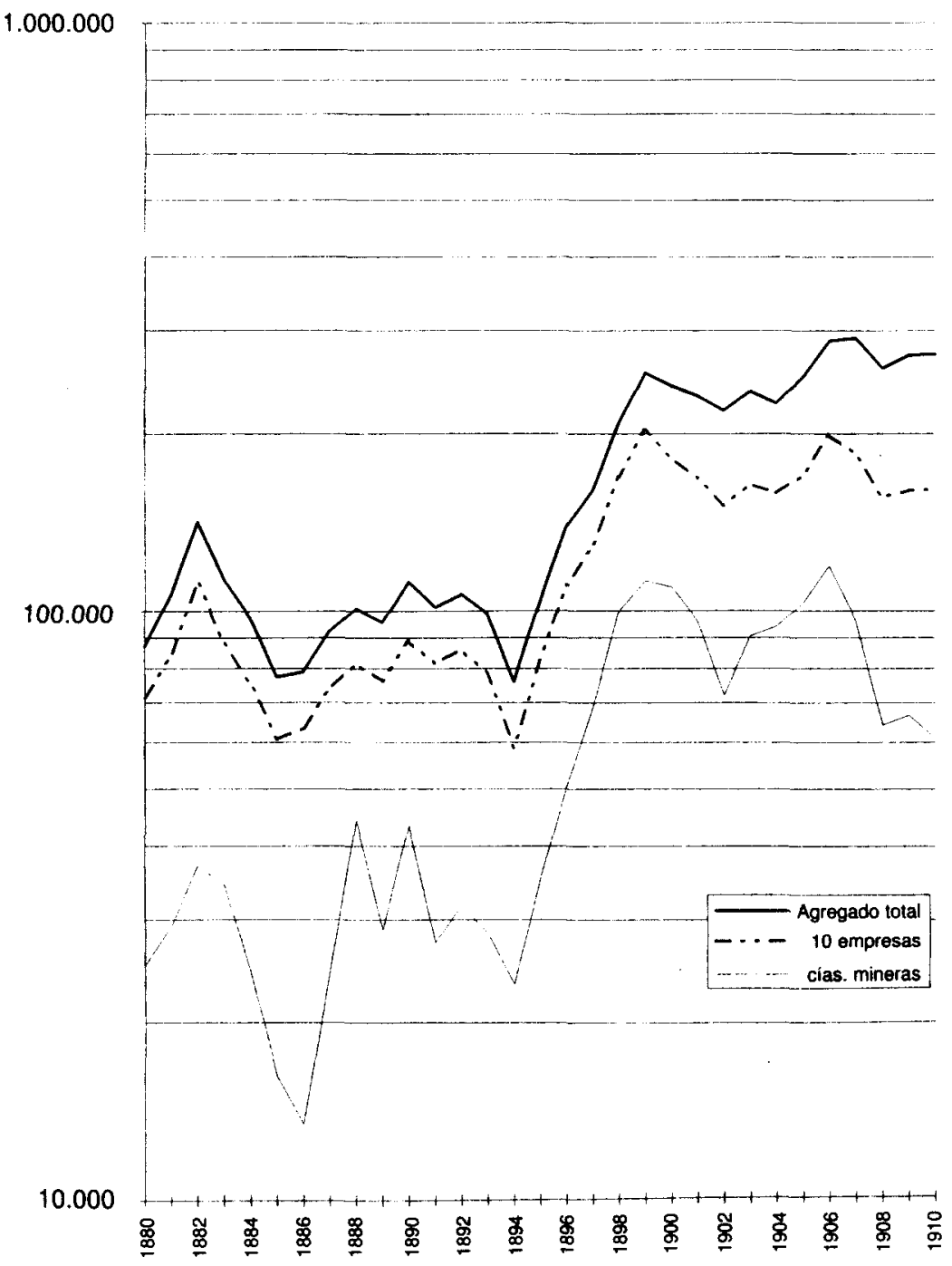




\section{CUADRO 2}

Número de series que componen el indice agregado

\begin{tabular}{|c|c|c|c|}
\hline$A \bar{n} o$ & & Año & \\
\hline $1880 \ldots \ldots \ldots \ldots$ & 10 & $1935 \ldots \ldots \ldots \ldots$ & 94 \\
\hline 1885 & 12 & $1940 \ldots \ldots \ldots \ldots$ & 130 \\
\hline 1890 & 14 & $1945 \ldots \ldots \ldots \ldots \ldots$ & 165 \\
\hline 1895 .......................... & 17 & $1950 \ldots \ldots$ & 210 \\
\hline $1900 \ldots \ldots \ldots \ldots \ldots$ & 25 & $1955 \ldots \ldots \ldots \ldots$ & 220 \\
\hline $1905 \ldots \ldots \ldots \ldots \ldots$ & 47 & $1960 \ldots \ldots \ldots \ldots \ldots$ & 181 \\
\hline $1910 \ldots \ldots \ldots \ldots \ldots$ & 82 & $1965 \ldots \ldots \ldots \ldots$ & 185 \\
\hline 1915 & 110 & 1970 & 117 \\
\hline $1920 \ldots \ldots \ldots \ldots \ldots \ldots$ & 129 & $1975 \ldots \ldots \ldots \ldots \ldots$ & 141 \\
\hline 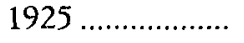 & 128 & $1980 \ldots \ldots \ldots \ldots \ldots$ & 121 \\
\hline $1930 \ldots \ldots \ldots \ldots$ & 147 & & \\
\hline
\end{tabular}

los cuatro colosos minero-metalúrgicos influyen sobremanera en el índice agregado. Son los causantes de las alzas más intensas y de las caídas más espectaculares. Contemplando el gráfico es imposible no sacar la conclusión que fueron el motor del formidable auge de 1894-1899. ¿Fue realmente así? A buen seguro, mi estimación adolece de un sesgo optimista en los años finiseculares al sobrevalorar el peso de las compañías mineras. Téngase en cuenta que una parte de los beneficios que entonces amasaron se debió a la depreciación de la peseta, circunstancia de la que posiblemente no sacaron provecho la mayoría de empresas del país ${ }^{13}$. En cambio, el auge de creación de sociedades no influyó grandemente en el agregado ${ }^{14}$. Con

${ }^{13}$ Los beneficios publicados por las sociedades mineras en cuestión están denominados en libras esterlinas y francos franceses y belgas. Como que exportaban la práctica totalidad de los bienes que producian y el precio de los mismos estaba determinado por el mercado internacional, el incremento de los beneficios estuvo originado, en cierta medida, por la propia depreciación de la peseta. Un caso bien distinto debió ser el de la mayoría de las empresas industriales, que vendían toda su producción en el mercado interior. Las ventajas que pudo reportarles la protección frente a la competencia exterior derivada de la caída del tipo de cambio quizás se vio contrarrestada por el encarecimiento de los insumos procedentes del extranjero.

${ }^{14}$ Como es bien conocido, el boom de nuevas empresas tuvo un relieve excepcional. Véase Tafunell (1989). Sin embargo, tal fenómeno no ocasiona ninguna perturbación estadística apreciable en el índice. Las incorporaciones no son, en absoluto, espectaculares. En 1894 y 1895 sólo hay una (Hullera Española y Ferrocarriles de Santander a Bilbao, respectivamente); en 1896 se elevan a tres (Barcelonesa de Electricidad, Sevillana de Electricidad y Unión Española de Explosivos); en 1897, ninguna; en 1898, cuatro 
todo, no cabe duda que un índice basado en una muestra más amplia de empresas tendría un comportamiento menos dinámico en la década final del siglo XIX. Afortunadamente, a medida que nos adentramos en el siguiente la estimación se hace más robusta al ensancharse la base de datos.

Ahora bien, el problema más grave planteado por las fuentes no radica en los abundantes vacíos de datos, sino en la baja calidad de los que aportan. Es indudable que la fiabilidad de la serie calculada se resiente seriamente por este motivo. Aquí, por razones de espacio y de oportunidad, no podemos detenernos a examinar concienzudamente tales deficiencias. Baste saber que las fuentes ofrecen, de manera indiferenciada, cifras de resultados que corresponden a conceptos contables en absoluto homogéneos, siendo tarea ardua, y en ocasiones inasequible, discriminar los distintos conceptos. Importa saber que la maraña informativa no es enteramente, y quizás ni siquiera principalmente, imputable a los editores de estas publicaciones. La responsabilidad recae en los propios gestores de las sociedades, y, en última instancia, en la Administración. Sobre este extremo es oportuno citar la ponderada opinión de Martínez Méndez, que califica el modelo legal de cuenta de resultados pública de la banca - un sector más intensamente regulado que los demás, no se olvide - vigente hasta 1982 de "una insuficiencia rayana en el ridiculo» ${ }^{15}$. Hasta fecha tan tardía como la década de 1970 las sociedades mercantiles españolas carecieron de un marco normativo adecuado para la confección de una cuenta de resultados pública que fuese una imagen fiel de los mismos, o sea, que se caracterizase por la veracidad, claridad, completitud y exactitud ${ }^{16}$. A nuestros efectos, lo importante es que, dada la ausencia de principios normativos contables

(Ferrocarriles de La Robla, Acumulador Tudor, Carburos Metálicos y Unión Resinera), y en 1899, cuando culmina el alza de los beneficios, tan sólo dos (Industrial Castellana y Naviera Vascongada). Curiosamente, se acrecientan las incorporaciones al descender los beneficios. En 1900 ascienden a cinco, en 1901 a once y en 1902 a siete.

15 Martínez Méndez (1991), p. 65.

${ }^{16}$ España entró con un enorme retraso en el proceso de normalización contable, tanto en su vertiente legal como en la privada. En lo que respecta a la primera, la pieza clave ha sido, como en los otros países, el Plan Contable. En España el primer Plan General de Contabilidad se promulgó en 1973, tres o cuatro décadas más tarde que en Alemania, Francia, Suecia y otros Estados europeos. Respecto a la normalización contable en el ámbito profesional, hubo que esperar hasta la fundación, en 1979, de la Asociación Española de Contabilidad y Administración de Empresas (AECA) para que tuviesen lugar avances significativos por esta vía. En Inglaterra y Estados Unidos los principios de contabilidad generalmente aceptados por las organizaciones profesionales se sentaron entre 1880 y 1910. Por otra parte, la legislación tributaria y la Ley de Sociedades Anónimas de 1951 fijaban 
y legales, las empresas españolas tuvieron hasta muy recientemente total libertad para amortizar los activos depreciables y dotar provisiones para posibles pérdidas futuras, así como para mostrar o bien ocultar los fondos que destinaban a esos fines ${ }^{17}$. Esta falta de regulación acarreaba dos distorsiones contables irreparables en la cuenta de resultados. Una de ellas consistía en que las empresas tendían a no dotar provisiones. Éstas quedaban subsumidas dentro de las reservas voluntarias. Cuando había que imputar fallidos y otras pérdidas a estos fondos se hacía directamente, sin que quedase reflejado en la cuenta de resultados. La segunda distorsión tenía por origen la falta de regulación legal efectiva de las dotaciones a amortizaciones. Las empresas propendían a seguir una estrategia sumamente discreccional al respecto. Es de suponer que fácilmente ésta fuese procíclica en extremo: en los ejercicios que lograban elevados beneficios, destinaban una parte de los mismos al fondo de amortización; en los años en que los resultados eran mediocres no hacían ninguna dotación al fondo. Para empeorar aún más las cosas, debido a esta tendencia a la erraticidad en la formación del fondo de amortizaciones, a la opacidad de los estados financieros publicados por las sociedades $y$ a un procesamiento no bastante cuidadoso de los mismos por parte de los editores de los AFSAE, éstos no suelen consignar, durante la primera mitad del siglo, la partida destinada a amortizaciones aun cuando exista y luzca en la cuenta de pérdidas y ganancias inserta en la memoria del ejercicio. En definitiva, y como sucede con frecuencia en el terreno de la reconstrucción estadística histórica, debemos aceptar como inputs registros cuantitativos - contables, en este caso- escasamente exactos y precisos.

unos preceptos extremadamente simples sobre la descomposición de la cuenta de pérdidas y ganancias. Véase Sánchez Fernández Valderrama (1989).

17 La Ley de Reforma Tributaria de 1940 contenía disposiciones concretas sobre las amortizaciones e incluso enunciaba, sin fijarlos efectivamente, los coeficientes máximos de las mismas. La Ley de Sociedades Anónimas de 1951 establecía que el activo patrimonial de la empresa debería amortizarse anualmente en función de la vida de dicho activo. Sin embargo, hubo que esperar hasta la promulgación de una orden del Ministerio de Hacienda de 1965 sobre coeficientes máximos y mínimos de amortización para que las sociedades aplicasen de forma general y sistemática la dotación de amortizaciones legal. Véase Unzueta (1978), pp. 118-121.

Por lo que se refiere a las provisiones para insolvencias y otras pérdidas, la adopción del marco legal es aún más reciente. La primera norma, de alcance restringido, y referida únicamente a la banca, fue promulgada en 1968. Con carácter general para todas las empresas, se publicó en 1977 una orden ministerial y un real decreto marcando límites a las dotaciones a provisiones para insolvencias. El Reglamento sobre el Impuesto de Sociedades aprobado en 1982 impuso definitivamente la obligación de dotar provisiones por un porcentaje de los créditos morosos. 
Porque, en la práctica, la alternativa metodológica es... sencillamente ninguna, o sea, continuar indefinidamente sin conocer cuál fue la evolución de los beneficios de la empresa española en períodos anteriores a los dos últimos decenios.

En lo que se refiere al sistema de ponderación de las series elementales que integran el índice, es obligado notar que el método de cálculo de un índice agregado de los beneficios difiere radicalmente del usado habitualmente para elaborar series de otras macromagnitudes. La forma más común y familiar para economistas e historiadores de la economía de evaluar el valor agregado de una variable macroeconómica consiste en la construcción de un agregado de números índices de series individuales representativas a las que se aplica una ponderación explícita. Sin embargo, para variables saldo como los resultados de las empresas, que no tan sólo tienden a ser sumamente volátiles, sino que pueden arrojar valores negativos, los métodos de agregación basados en números índices son inadecuados hasta el punto que debe descartarse de plano su utilización ${ }^{18}$. Así pues, no hay más remedio que calcular el valor agregado de los beneficios mediante la adición de las series individuales. Esto tiene dos implicaciones que conviene tomar en cuenta. La primera es que con este método las series que cada año.componen el sumando no tienen ninguna ponderación reconocida. Lo cual es lo mismo que decir que cada serie elemental influye en la variación interanual del agregado en función del peso que tenga en cada momento, esto es, de lo que represente el valor de los beneficios de la serie en cuestión en relación al valor del conjunto ${ }^{19}$. La segunda implicación, obvia y de trascendental importancia a efectos prácticos, estriba en que las series deben ser de la misma naturaleza y estar medidas con la misma unidad, a diferencia del método de números índices en que no es indispensable satisfacer tal requisito. A cambio de imponer esta restricción, el método de agregación pura brinda una gran ventaja sobre el de los números índices: nos evita todas las distorsiones originadas por el desfase de la base de ponderación.

${ }_{18}$ El lector que tenga curiosidad por conocer los valores aberrantes que se obtienen del cálculo de un índice agregado basado en números índices ponderados puede consultar Tafunell (1996), pp. 20-27.

${ }_{19}$ Mientras que con un índice agregado basado en números índices los valores (beneficios) de cada serie están ponderados por otra variable de la cual son función, como por ejemplo los recursos propios. Es evidente que los índices resultantes de aplicar uno y otro método presentarán discrepancias tanto más grandes cuanto mayores sean las diferencias existentes en las tasas de rentabilidad del capital (o de la variable que se use como ponderador). 
Cumplir el imperativo de computar valores comparables en términos absolutos encierra dificultades, pues, como acabo de indicar, las fuentes no facilitan información sobre una categoría determinada de excedentes empresariales. Por consiguiente, previamente al cálculo del agregado ha habido que efectuar una operación de depuración y estandarización de los datos, que ha exigido estimar una porción importante de los mismos. El concepto contable de resultados que he empleado es el de los «recursos generados»-también denominado «resultado económico bruto total»-, esto es, el resultado neto total más las dotaciones a amortizaciones y provisiones ${ }^{20}$. Habida cuenta de las deformaciones de las cuentas de resultados publicadas a las que hacía mención, este concepto de resultados es el único que posibilita una cuantificación consistente.

La elaboración de la serie agregada no acaba ahí, es decir, no se alcanza sin más que proceder a una simple suma de las series elementales de recursos generados. Dado que las incorporaciones y ceses de las series se producen por factores fortuitos, ocasionan aumentos o disminuciones espurios en el agregado. Éste es el típico problema creado por las lagunas en la información, al que en la agregación de series de números índices se hace frente con una solución técnicamente bien sencilla: un ajuste en la serie agregada que elimina el sesgo al alza o a la baja causado por la entrada o salida, respectivamente, de una o más series. Pero, en el caso que nos ocupa, tal recurso estadístico queda invalidado por el corto número de series con que contamos al comienzo. En estas circunstancias, realizar ajustes en el agregado al dar entrada a nuevas series acarrearía la neutralización del grueso de la masa de beneficios, con lo cual la tendencia a largo plazo del agregado dependería sobremanera de la evolución de los resultados de las empresas presentes en él desde el principio. Por tanto, es necesario colmar de algún modo las lagunas informativas. La fórmula aplicada ha consistido en rellenar con beneficios estimados los tramos vacíos de aquellas series que se inician más tarde de la constitución de la sociedad, en rigor, de cuando ésta alcanzó el umbral de significatividad establecido ${ }^{21}$. He supuesto que estas sociedades lograron en los años en que carecemos de información la tasa de rentabilidad media del capital de las empresas

${ }^{20}$ En el apéndice de Tafunell (1996) figuran las series de los recursos generados «reales» o estimados de todas las sociedades que forman parte del agregado.

${ }^{21}$ Véase nota 10 . Téngase en cuenta que, por coherencia con los criterios de selección antes especificados, la incorporación o cese de los beneficios de una sociedad en mi serie agregada no necesariamente se corresponde con su constitución o disolución. Un incremento o disminución marginales del tamaño de las empresas en el umbral de la significación les confiere o retira la existencia en mi estimación. 
integradas en el cómputo del agregado. Es posible que éste no sea el criterio más razonable al nivel de la serie individual, pero sí es perfectamente coherente para el cálculo del agregado. Adviértase que es el único supuesto que cumple la condición de neutralidad de la estimación.

\section{CONTRASTACIÓN CON OTRAS ESTIMACIONES}

Como he indicado, el ejercicio de reconstrucción estadística que se muestra en estas páginas apenas cuenta con precedentes. Casi todas las elaboraciones existentes proceden de instituciones públicas encargadas de la estimación de macromagnitudes básicas: el INE (Contabilidad Nacional), el Banco de España (Central de Balances), el Instituto de Estudios Fiscales (Las cuentas de las sociedades), el Servicio de Estudios del Banco de Bilbao (Renta Nacional). Ninguno de estos organismos ha efectuado cálculos retrospectivos sobre los excedentes empresariales, por lo que las series de éstos dan comienzo prácticamente con el primer año de publicación de las estadísticas que han venido elaborando hasta la actualidad. Así, el año de inicio es 1954 en el caso del INE (CEN), 1955 en el del Servicio de Estudios del Banco de Bilbao (en adelante, SEBB), 1981 en el de la Central de Balances del Banco de España y 1989 en el del IEF ${ }^{22}$.

Con anterioridad a 1954, lo poco que hasta ahora sabíamos acerca de los resultados empresariales procedía de la historiografía económica. Dejando de lado las monografías de empresas, donde lógicamente los investigadores han circunscrito su empeño cuantificador a los resultados de la firma analizada, se trata de incursiones puntuales, confinadas a un corto arco temporal, en las que sus autores utilizan o construyen índices de beneficios con la finalidad de emplearlos como un indicador más de coyuntura económica o para fundamentar ciertas afirmaciones sobre la trayectoria de determinadas empresas y sectores. El más conocido de tales ejercicios es el celebérrimo estudio de Roldán y García Delgado (1973). Las obras de Comín (1988) y Catalán (1995) son dos buenas, y singulares, ilustraciones del manejo limitado de esta variable por parte de los analistas de nuestro pasado económico. En realidad, el único ejercicio monográfico de estimación de una serie histórica de beneficios no se lo debemos a un estudioso de la historia económica, sino a un investigador del sistema

22 Echevarría y Herrero (1989), sirviéndose de las cifras de Contabilidad Nacional del INE y algunas estimaciones anteriores, más las de riqueza nacional, construyeron una serie de la rentabilidad financiera del sector industrial desde 1940. 
financiero, Martínez Méndez (1991). Pero su ensayo, de un altísimo rigor técnico y analítico, escudriña una angosta parcela del vasto campo histórico ${ }^{23}$.

En resumidas cuentas, la serie que aquí presento tiene pocos referentes con los que compararse. Los mejores tests que por el momento podemos efectuar consisten en el cotejo de mi serie con las formadas por las estimaciones del INE y el SEBB (véase cuadro 3) ${ }^{24}$.

Por lo que se refiere a la primera, bueno es recordar que, como muchos autores han subrayado, la renta nacional estimada por el organismo oficial de estadística desde el enfoque del ingreso (Cuenta de Explotación de la Economía) es sumamente limitada en el detalle funcional. Distingue tan sólo entre las rentas del trabajo por cuenta ajena, los impuestos ligados a la producción y a la importación y el excedente bruto de explotación. Dentro de este último concepto únicamente se precisa el consumo de capital fijo $-\mathrm{y}$, por diferencia, el excedente neto de explotación-. Debemos conformarnos, pues, para nuestro ejercicio de control con poner en relación mi serie con el mencionado excedente bruto de explotación. Puesto que éste contiene otras fuentes de renta, carece de sentido comparar los valores absolutos. Por ello, en el gráfico que nos ha de servir para contrastar ambas series (véase gráfico 3 ) he expresado éstas en números índices tomando como base 100 el año 1981.

El gráfico resulta tranquilizador. Las dos curvas tienen una pendiente casi coincidente. Los beneficios, según mi estimación, han aumentado a una tasa anual del 15,1 por 100 , en tanto que el excedente bruto de

${ }^{23}$ Tanto desde el punto de vista cronológico — cubre el período 1970-1989- como sectorial - la banca-, el trabajo de Martínez Méndez supone una aportación limitada, máxime por no ser aplicable su método de elaboración a otros sectores y períodos. Lo cual no hay que entenderlo, en modo alguno, como un reproche o crítica a un estudio que es magnífico. Simplemente, el autor persigue unos objetivos distintos a los míos.

${ }^{24}$ En lo que se refiere al excedente bruto de explotación de la economía, utilizo las cifras que da Ezequiel Uriel (1986), con las que se salva el problema del enlace de series de CNE con bases y sistemas de contabilidad distintos. Los datos se encuentran en la primera columna de la tabla de la página 97.

Los valores de la segunda columna del cuadro, que recogen la estimación del SEBB, resultan de la adición de las rúbricas «Beneficio retenido por las sociedades y empresas» y «Dividendos de acciones», dentro de las rentas de capital, más las de «Impuesto sobre sociedades y entidades» e «Impuesto industrial. Cuota de beneficios», dentro de las rentas del sector público. He tenido que salvar un pequeño escollo: la serie bomogénea 1955-1975, elaborada por la propia institución, tan sólo especifica el beneficio retenido. Como las publicaciones en que se ofrecen las estimaciones de cada año sí dan noticia de los otros conceptos, he obtenido el agregado de los beneficios después de amortizaciones sumando los conceptos indicados y ajustándolo a la magnitud de la Renta Interior Neta de la serie homogénea. Véase Banco de Bilbao (1978 y varios años). 


\section{CUADRO 3}

Estimaciones de los beneficios, en millones de pesetas corrientes

\begin{tabular}{|c|c|c|c|}
\hline$A \bar{n} o$ & $I N E^{1}$ & $S E B B^{2}$ & Tafunell $^{3}$ \\
\hline $1954 \ldots \ldots \ldots \ldots \ldots$ & 196.034 & - & 27.880 \\
\hline $1955 \ldots \ldots \ldots \ldots \ldots$ & 217.741 & 21.846 & 37.001 \\
\hline $1956 \ldots \ldots \ldots \ldots \ldots$ & 249.069 & - & 42.102 \\
\hline $1957 \ldots \ldots \ldots \ldots \ldots$ & 293.223 & 29.103 & 52.551 \\
\hline $1958 \ldots \ldots \ldots \ldots \ldots$ & 343.114 & - & 72.242 \\
\hline 1959 .................. & 343.022 & - & 72.567 \\
\hline $1960 \ldots \ldots \ldots \ldots \ldots . . . . . .$. & 340.413 & 46.429 & 80.364 \\
\hline 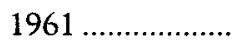 & 395.766 & - & 95.060 \\
\hline $1962 \ldots \ldots \ldots \ldots \ldots . . . . . .$. & 465.195 & 69.769 & 100.540 \\
\hline $1963 \ldots \ldots \ldots \ldots \ldots$ & 536.117 & - & 100.833 \\
\hline 1964 ................... & 590.436 & 85.559 & 109.918 \\
\hline $1965 \ldots \ldots \ldots \ldots \ldots$ & 675.614 & - & 129.638 \\
\hline $1966 \ldots \ldots \ldots \ldots \ldots$ & 751.624 & 一 & 140.593 \\
\hline 1967 .................... & 818.288 & 121.193 & 148.058 \\
\hline $1968 \ldots \ldots \ldots \ldots \ldots$ & 940.738 & - & 178.651 \\
\hline $1969 \ldots \ldots \ldots \ldots \ldots$ & 1.049 .897 & 168.567 & 216.438 \\
\hline $1970 \ldots \ldots \ldots \ldots \ldots$ & 1.148 .329 & - & 241.591 \\
\hline $1971 \ldots \ldots \ldots \ldots \ldots$ & 1.285 .610 & 260.951 & 249.424 \\
\hline $1972 \ldots \ldots \ldots \ldots \ldots$ & 1.449 .220 & - & 319.424 \\
\hline $1973 \ldots \ldots \ldots \ldots . . . . . . . . . .$. & 1.709 .122 & 353.871 & 440.896 \\
\hline $1974 \ldots \ldots \ldots \ldots \ldots . . . . . . .$. & 2.144 .538 & - & 471.407 \\
\hline $1975 \ldots \ldots \ldots \ldots \ldots$ & 2.450 .819 & 372.291 & 511.004 \\
\hline $1976 \ldots \ldots \ldots \ldots \ldots . . . . . . .$. & 2.929 .121 & - & 559.416 \\
\hline $1977 \ldots \ldots \ldots \ldots \ldots . . . . . .$. & 3.647 .938 & 486.680 & 669.913 \\
\hline $1978 \ldots \ldots \ldots \ldots \ldots$ & 4.561 .493 & - & 696.833 \\
\hline 1979 ................... & 5.312 .282 & 724.282 & 829.807 \\
\hline $1980 \ldots \ldots \ldots \ldots \ldots$ & 6.307 .634 & - & 949.547 \\
\hline $1981 \ldots \ldots \ldots \ldots \ldots$ & 7.136 .035 & 810.231 & 1.230 .949 \\
\hline
\end{tabular}

1 Excedente bruto de explotación de la economía. Véase texto.

2 Beneficio neto antes de impuestos. Véase texto.

${ }^{3}$ Recursos generados por el conjunto de sociedades anónimas, calculados mediante extrapolación del agregado de recursos generados de las sociedades comprendidas en la muestra. Véase Tafunell (1996), p. 48.

explotación de la economía, de acuerdo con la evaluación del INE, ha crecido a una tasa del 14,2 por 100 . Cierto es que el gráfico revela 


\section{GRÁFICO 3 \\ Excedente de explotación de la economía y beneficios, en pesetas corrientes $(1981=100)$}

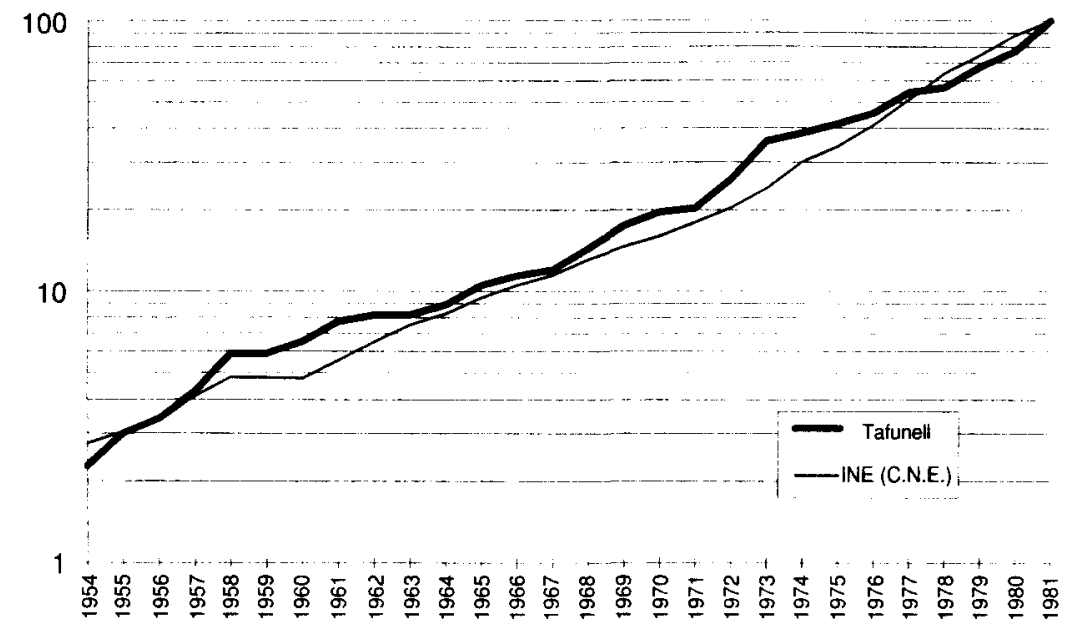

diferencias en el perfil de las curvas. El excedente de explotación de la economía muestra un comportamiento muy lineal, casi rectilíneo -midiéndolo, no se olvide, en términos nominales-. En cambio, el curso alcista de los beneficios traza ondulaciones cíclicas. Estas discrepancias son fácilmente explicables, habida cuenta que la primera variable es una magnitud económica sensiblemente más agregada y un tanto menos volátil que los recursos generados por las sociedades. Es interesante advertir que las discrepancias entre ambas series se reducen a la intensidad de las variaciones interanuales, no a su dirección. Es natural que los excedentes empresariales tiendan a variar más marcadamente y con mayor velocidad que el excedente del conjunto de la economía.

El contraste con la elaboración del SEBB guarda mayor interés, dado que, a diferencia de la magnitud calculada por el INE, nos brinda una estimación bastante pormenorizada de la renta nacional - para ser más exactos, renta interior neta- por el lado del ingreso. Gracias a este detalle, podemos obtener con toda facilidad una estimación del agregado de beneficios que tan sólo se diferencia del que yo he calculado en que excluye las amortizaciones. El gráfico 4 confronta la evolución de esta serie -desgraciadamente, de carácter bianual, e incluso, en un par de ocasiones, 
trianual- con la que yo he elaborado, expresadas ambas en números indices.

Es manifiesto que las curvas siguen una evolución similar. Al igual que con respecto a la elaboración del INE, el ritmo de crecimiento a largo plazo de mi serie es muy semejante a la construida por el SEBB. Esto es compatible con algunas discordancias en la evolución a más corto plazo. En los años 1971 y 1979 mis cifras se apartan un tanto de las obtenidas por el SEBB. Se aprecia con claridad una diferencia algo significativa en el período que va de 1960 (o 1961) a 1971. Para el SEBB - y también para el INE - fue más expansivo de lo que mis cálculos conceden. Con todo, el balance es, a mi entender, francamente satisfactorio. Los márgenes de discrepancia son reducidos y perfectamente tolerables, tratándose de dos elaboraciones que miden dos magnitudes contables no exactamente iguales. Es verosímil que las diferencias observadas obedezcan simplemente a las variaciones en el peso relativo de las amortizaciones. Aunque no sería lícito ocultar que pueden abrigarse algunas dudas sobre el verdadero grado de independencia de mi estimación con respecto a la del SEBB, e incluso la del INE. No es descabellado conjeturar que se hayan basado en las mismas fuentes. Añádase a ello, para valorar en su justa medida el sentido de las comparaciones anteriores, que el período abarcado en ellas representa tan sólo una cuarta parte del que cubre mi ensayo.

Lo anterior induce a extender la contrastación a los índices de beneficios del conjunto empresarial producidos por la historiografía, esto es, los construidos por Roldán-García Delgado y Comín, incluso a sabiendas de que de estas comparaciones difícilmente podremos dilucidar el grado de fiabilidad de mi cuantificación. Mi elaboración se basa en la misma fuente que emplearon Roldán-García Delgado, y comparte con el índice que ellos calcularon una buena parte de las empresas seleccionadas. En cuanto a la serie utilizada por Comín para los años 1923-1934, procede de una estadística publicada en 1936 por el Consejo Superior de Cámaras de Comercio de España, cuyo origen muy probablemente sea la misma fuente explotada por Roldán-García Delgado y por mí. El uso de esta serie para contrastar el grado de consistencia de la que aquí publicamos se ve complicado por el hecho de que está deflactada por la renta nacional ${ }^{25}$.

${ }^{25}$ Comín (1988), vol. II, pp. 829-32. Ignoro el origen de las cifras de renta nacional utilizadas por este autor. He supuesto que, como en muchas otras ocasiones a lo largo de la obra, se ha valido de la serie de Gasto Nacional Bruto de A. Carreras, por concederle mayor fiabilidad que las anteriores mediciones. Como disponemos ahora de una evaluación más refinada, que debemos a Prados (1995), de la que me sirvo en este ensayo, he ajustado 


\section{GRÁFICO 4}

Estimaciones de beneficios, en pesetas corrientes $(1981=100)$

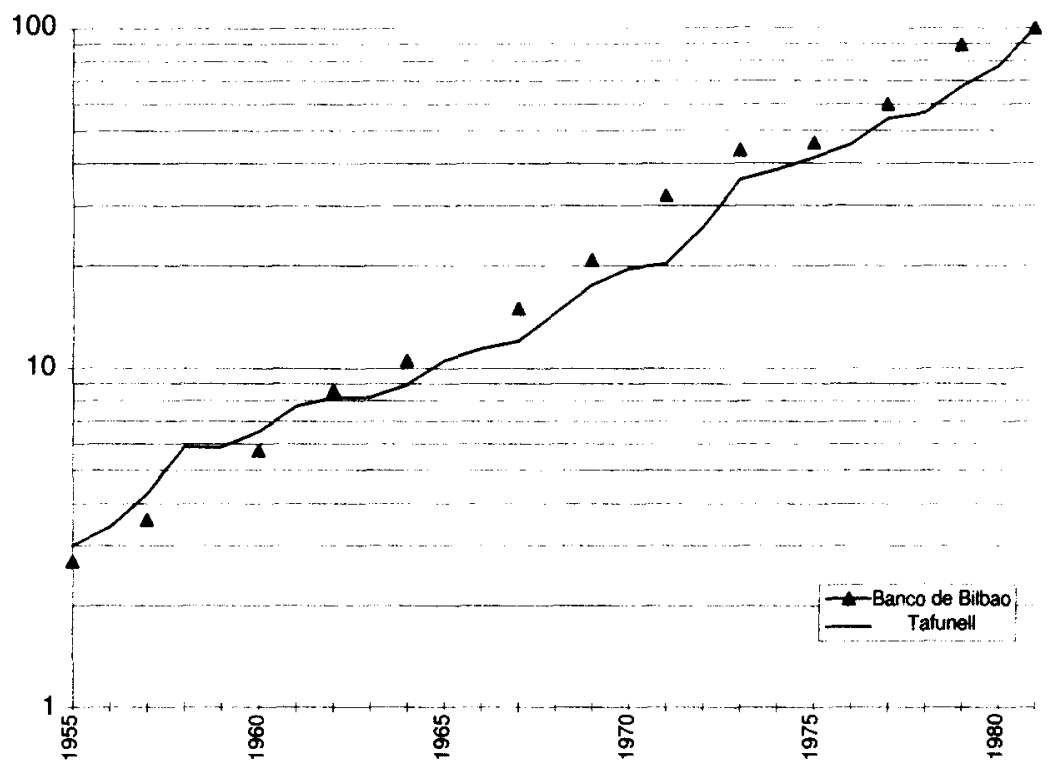

Existe una gran concordancia entre la serie de Roldán-García Delgado y la mía, como revela el gráfico 5 . No podía ser de otra manera. Todas las diferencias entre ambas se condensan en lo siguiente. Si diésemos crédito a mi reconstrucción estadística, el alza de los beneficios no habría tenido tanta amplitud, y, en la fase descendente del ciclo, la caída habría sido menos intensa pero más continuada. Cabe advertir, asimismo, otras dos discrepancias de menor entidad: la crisis provocada por el estallido de la guerra habría sido más aguda de lo que la estimación de Roldán-García Delgado concede, y la recuperación episódica que, conforme a ésta, tuvo lugar en el año 1920 sería, si yo estuviese en lo cierto, totalmente inexistente. A fin de cuentas, todas estas disparidades son fácilmente explicables, ya que derivan del propio método de selección de las series elementales de beneficios empleado por Roldán-García Delgado. El criterio que aplicaron no fue otro que recoger los datos de resultados registrados

las cifras que proporciona Comin para que ambas series estén referidas a la misma magnitud, es decir, el PIB a precios de mercado en pesetas de 1913. 


\section{GRÁFICO 5}

Estimaciones de beneficios, en pesetas corrientes $(1913=100)$

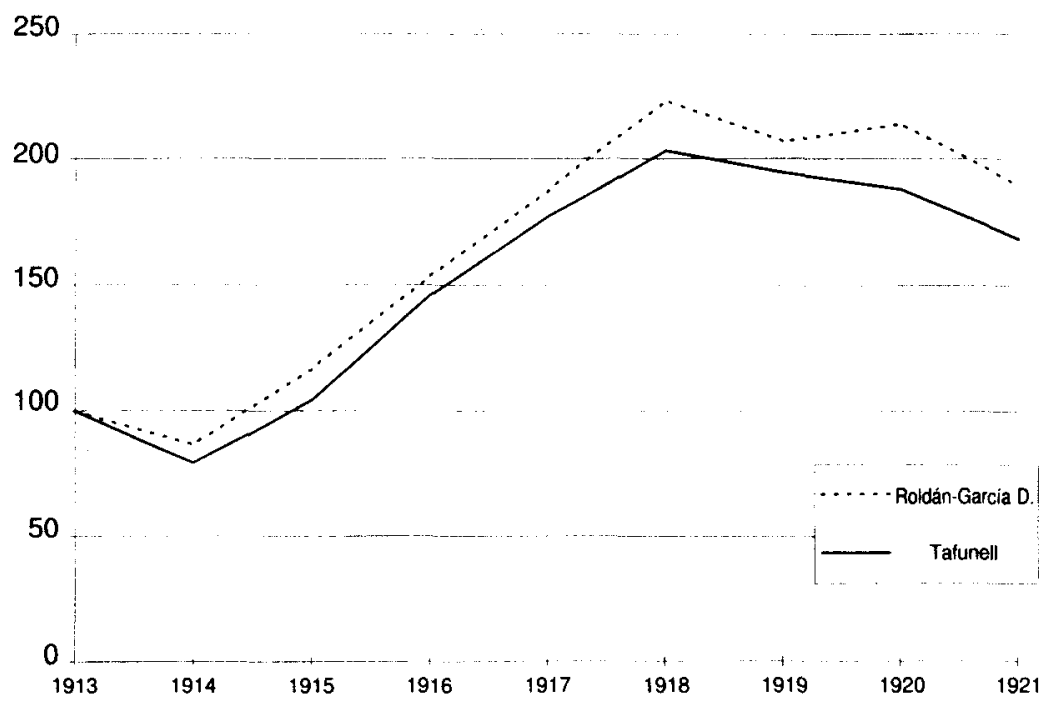

en los AFSAE de todas aquellas empresas que en alguno de los años del período estudiado (1913-1921) obtuvieron unos beneficios superiores al millón de pesetas ${ }^{26}$. Es obvio que, guiándose por este principio, la estimación resultante incorpora un sesgo alcista al primar las entidades más capaces de generar abultados excedentes - no necesariamente las de mayores dimensiones-, por lo cual tiende a exagerar el aumento ocurrido en la fase expansiva, y, acaso, a infravalorar las disminuciones acaecidas en la etapa de contracción. Por esta razón, además de la desigual representatividad de uno y otro índice, entiendo que la serie que presento es más sólida que la de Roldán-García Delgado.

Las conclusiones que se desprenden de la comparación de mi cuantificación y la de Comín (véase gráfico 6) son de otro tenor. Llama la atención que sean tan numerosos los desencuentros. Únicamente en los años 1928, 1930 y 1931 las dos curvas van en la misma dirección, e incluso en este último hay una diferencia entre ambas muy apreciable

${ }^{26}$ Roldán-García Delgado (1973), p. 114. 


\section{GRÁFICO 6 \\ Estimaciones de beneficios, en porcentaje del PIB}

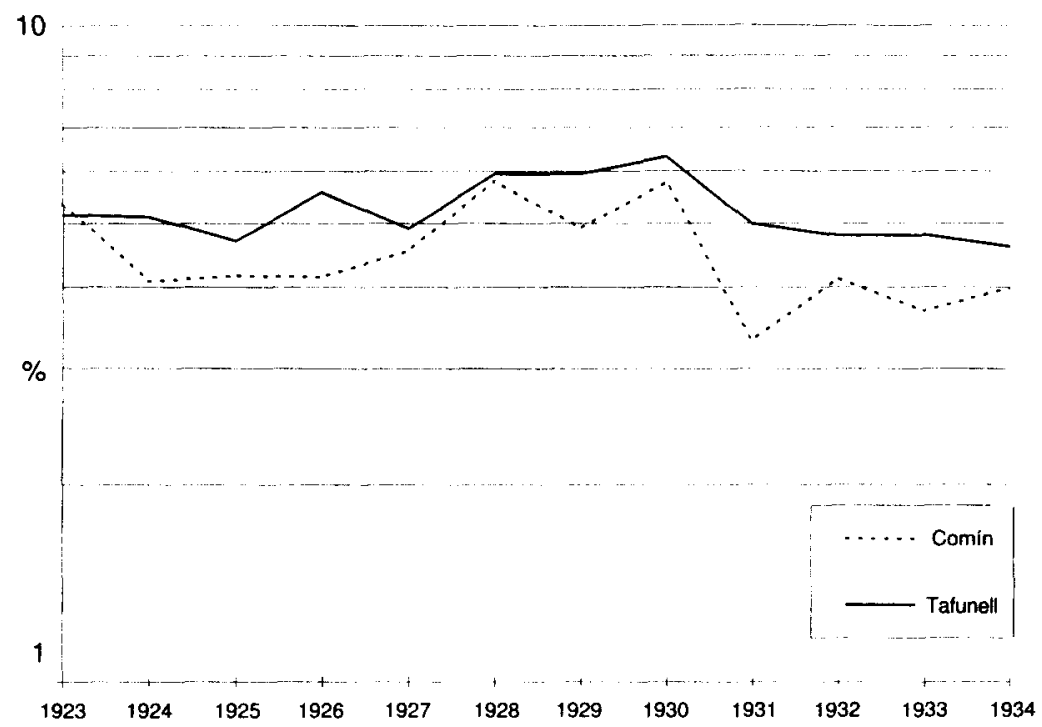

en la intensidad del descenso. En el resto del período siguen trayectorias claramente diferenciadas, en tasas de variación interanual, bien sea porque una sufre una fuerte alza o caída mientras la otra permanece estable (1924-26, 1929, 1933), o bien porque marchan en direcciones opuestas (1927, 1932, 1934). La mayor similitud entre las curvas reside en el nivel de sus valores. Sin embargo, esto no significa que tengan un grado de cobertura parejo. De hecho, al desconocer cómo ha sido elaborada la serie que presenta Comín, la comparación nos deja sumidos en un mar de dudas.

\section{LA EVOLUCIÓN DE LOS BENEFICIOS: FLUCTUACIONES CÍCLICAS Y TENDENCIAS A LARGO PLAZO}

Los excedentes empresariales, en términos reales, se han multiplicado, aproximadamente, cuarenta veces en el siglo abarcado por el estudio. Esto significa una tasa de crecimiento medio anual acumulativo del 3,71 por 
$100^{27}$. Las diferencias de ritmo de crecimiento, por períodos decenales, quedan recogidas en el cuadro 4 . Como se advierte, ha habido cinco decenios de fuerte crecimiento y otros tantos en los que éste ha sido débil o incluso negativo. Las décadas de mayor dinamismo han sido, por orden cronológico, 1890-1900, 1920-1930 y las comprendidas entre 1940 y 1970. Esto es verosímil, por estar en consonancia con el saber acumulado por los historiadores económicos. Sorprende, sin embargo, que las alzas de los años cuarenta y, sobre todo, de los sesenta queden por debajo de las acaecidas en las décadas 1890-1900 y 1920-1930. Pero hay que tener en cuenta que, como he mostrado en el apartado anterior, probablemente mi estimación exagera el alza finisecular. En lo que respecta a los períodos decenales menos expansivos, sobresalen los que inauguran la centuria (1900-1920) y el último (1970-1981). La década de 1880-1890 fue de crecimiento moderado, y en la de $1930-1940$ se asistió a una caída de los beneficios como consecuencia de la depresión económica y la Guerra Civil.

La división en períodos decenales se revela no del todo satisfactoria. Una periodización atenta a las inflexiones de los movimientos de largo plazo puede caracterizar de modo más exacto los distintos ritmos de crecimiento que han experimentado los beneficios en el transcurso del siglo. De una primera lectura del anexo 1 y el gráfico 1 se desprende que en el trend secular fuertemente alcista subyacen algunas tendencias a largo plazo. En mi opinión, su delimitación temporal es la que expresa la tercera columna del cuadro comentado, sin perjuicio de que haya otras periodizaciones posibles igualmente válidas.

La imagen que dibujan las tasas de crecimiento de la columna derecha del cuadro 4 es, en efecto, bastante más razonable que la trazada por los aumentos decenales. Las etapas de estancamiento se alternan con las expansivas y la intensidad de unas y otras parece acorde con la evolución económica general. En una primera fase, que comprende los tres primeros lustros, los beneficios avanzan cansinamente. A partir de 1895 experimentan, como hemos visto, una gran aceleración. De hecho, los resultados empresariales entran en una dinámica de crecimiento vigoroso de largo alcance, que no concluye hasta 1930. Desde este año y durante nada menos que un ventenio (1950 ó 1951) las cuentas de resultados de las empresas españolas apenas progresaron. A esta larga etapa depresiva

${ }^{27}$ Calculada en relación a los años inicial y terminal de la serie. La tasa de crecimiento acumulativo asciende al 3,51 por 100 anual si en lugar de tomar únicamente los dos años extremos se considera la media cuatrienal (1880-83/1978-81). 


\section{CUADRO 4}

Tasas de crecimiento anual de los beneficios, 1880-1981

\begin{tabular}{|c|c|c|c|}
\hline $1880-1890 \ldots \ldots \ldots \ldots$ & 3,32 & & \\
\hline $1890-1900 \ldots \ldots \ldots \ldots . . . . .$. & 6,74 & $1880-1895 \ldots \ldots \ldots \ldots$ & 1,74 \\
\hline $1900-1910 \ldots \ldots \ldots \ldots$. & 1,24 & $1895-1930 \ldots \ldots \ldots \ldots$ & 4,49 \\
\hline $1910-1920$................. & 1,13 & 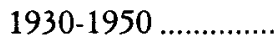 & 1,12 \\
\hline $1920-1930 \ldots \ldots \ldots \ldots . . . .$. & 5,97 & 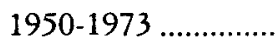 & 8,31 \\
\hline $1930-1940 \ldots \ldots \ldots \ldots . . . .$. & $-2,97$ & $1973-1981 \ldots \ldots \ldots \ldots . . . .$. & $-2,09$ \\
\hline $1940-1950 \ldots \ldots \ldots \ldots . . . . .$. & 5,38 & $1880-1935 \ldots \ldots \ldots \ldots$ & 3,08 \\
\hline $1950-1960 \ldots \ldots \ldots \ldots . . . .$. & 10,36 & $1935-1981 \ldots \ldots \ldots \ldots$ & 4,48 \\
\hline $1960-1970 \ldots \ldots \ldots \ldots . .$. & 5,36 & $1880-1981 \ldots \ldots \ldots \ldots$ & 3,71 \\
\hline 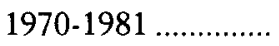 & 1,60 & & \\
\hline
\end{tabular}

sucedió otra de hipercrecimiento entre 1950 y 1973. Se produjo entonces, en paralelo con la definitiva industrialización y modernización de la economía española, una auténtica explosión de los beneficios. Finalmente, desde 1974 se abrió una nueva etapa, no concluida en el año terminal de mi estimación, caracterizada por una contracción inusitadamente severa: el índice agregado disminuyó a una tasa anual superior al 2 por $100^{28}$. Lo más llamativo, por novedoso, de esta cronología es el punto de arranque de la segunda etapa. De todos modos, el cambio de tendencia del último lustro de la pasada centuria no constituye un fenómeno completamente insospechado. Cada vez disponemos de más evidencia empírica que señala un viraje histórico de nuestra economía en esos años ${ }^{29}$. En otro orden de cosas, cabe destacar que el crecimiento de la primera parte del siglo analizado (1880-1935) fue sensiblemente inferior al de la segunda parte (1935-1981). Podríamos concluir que, en definitiva, todas las pautas de comportamiento a largo plazo de los beneficios que el cuadro 4 y el gráfico 1 reflejan son predecibles, a la luz de la marcha de la economía española. Volveré sobre esta cuestión en el apartado siguiente.

${ }^{28}$ No se olvide que los beneficios calculados incluyen las amortizaciones, que se acrecientan grandemente en este periodo como consecuencia, entre otras razones, de que la crisis acelera en extremo la obsolescencia de los equipos de las empresas. Una estimación de los beneficios netos arrojaría tasas de decrecimiento más elevadas.

${ }^{29}$ La serie del PIB elaborada por Leandro Prados (1995) también muestra con claridad un cambio de tendencia en el año 1896, aunque el autor lo pase por alto al formular sus esquemas de periodización. Curiosamente, la inflexión sintoniza perfectamente con la cronología de ciclos largos propuesta por Kondratieff. 
No son, empero, los movimientos de larga duración el rasgo más sobresaliente del perfil de la serie de beneficios agregados. Al contemplar el gráfico 1, seguramente lo que primero salta a la vista es la acusada ciclicidad de la curva. Conforma unas fluctuaciones bien definidas, que parecen estar estrechamente ligadas al ciclo económico. En estas líneas no puedo sino limitarme a enunciar dichas fluctuaciones: 1880-1885, 1885-1894, 1894-1904, 1904-1908, 1908-1914, 1914-1920, 1920-1934 -un ciclo tan extrordinariamente dilatado que puede conjeturarse que envuelve dos ciclos embrionarios, subsumidos en uno solo por la fuerza de la expansión de los años veinte-. Tras el paréntesis de la guerra, las fluctuaciones parecen desvanecerse por la intensidad del alza. Hasta la crisis de los años setenta, las fases descendentes de los ciclos consisten en desaceleraciones del crecimiento, más que en caídas absolutas de la macromagnitud. Un análisis algo más detenido de la curva desvela la cronología de los ciclos posteriores a la guerra: 1939-1946, 1946-1951, 1951-1956, 1956-1959, 1959-1963, 1963-1967, 1967-1971, 1971-1978.

Dejando a un lado la delimitación temporal de los movimientos a corto plazo, hay algunos episodios coyunturales que, a mi juicio, merecen algún comentario, o, al menos, una alusión. Es ocioso decir que mi selección es perfectamente subjetiva, $\mathrm{y}$, por ende, hay otras selecciones posibles. Al primero, por orden cronológico, de los fenómenos coyunturales que, en mi opinión, deben ser remarcados ya he hecho referencia. Se trata del ciclo en el que se despliega el famoso auge finisecular. Aun descontando que esté exagerado un tanto en mi estimación, el ascenso de los beneficios debió ser más intenso que en la mayoría de las otras etapas expansivas. El siguiente pasaje que se hace merecedor de algún comentario es el ciclo bélico -de la Primera Guerra Mundial-. Pese a que no pasa desapercibido, está muy lejos de tener la relevancia que le han atribuido algunas tesis muy arraigadas en la historiografía económica española. Es de subrayar también la escasa profundidad de la crisis de principios de la década de 1930. Contrariamente a lo que suele pensarse, los beneficios no se hundieron durante la República. Como tampoco lo hicieron durante la contienda. En este último punto, la evolución de la serie acaso se antoje inverosímil. A primera vista resulta asombroso que no fuese mayor la caída de los excedentes empresariales. Posiblemente, para los años del conflicto, mi estimación peca de excesivo optimismo, y, en todo caso, es frágil, dada su baja representatividad y la circunstancial exclusión de los datos de las empresas que atravesaron mayores dificultades para desenvolver de forma mínimamente regular sus actividades. Al término de la conflagración tuvo 
lugar un fuerte relanzamiento de las rentas empresariales, en abierto contraste con la situación depresiva atravesada por la economía española. Podemos comprobar ahora algo que ya habían afirmado, sin una base empírica extensa, los contemporáneos e investigadores de la autarquía. Es interesante advertir que los años de la Segunda Guerra Mundial fueron los de mayor bonanza para los propietarios de las empresas, precisamente cuando el sistema productivo se enfrentó a las escaseces más severas. Pero el desbarajuste provocado por la persistencia de las restricciones y el funcionamiento irregular de los mercados al parecer acabaron afectando —en la segunda mitad de los años 1940 - la generación de beneficios extraordinarios. A partir de 1951, la reorientación de la política económica, la ayuda exterior y los logros del modelo industrializador imprimieron un formidable impulso a los beneficios. Como cabía esperar, su crecimiento se desaceleró, sin detenerse, al aplicarse las medidas preestabilizadoras y el Plan de Estabilización. Lo que no podíamos esperar es que no recobrasen la senda de la expansión hasta la segunda mitad de los años sesenta. En mi opinión, ahí reside el aspecto más enigmático del curso descrito por el índice de beneficios en el último medio siglo. No puedo dar una explicación convincente de por qué se sumieron entre 1961 y 1967 en una dinámica de estancamiento cuando, simultáneamente, la economía crecía de forma explosiva. Únicamente me atrevo a aventurar algunas conjeturas -ni siquiera hipótesis-. Helas aquí: la incapacidad del sector público empresarial —ampliamente potenciado y desarrollado en el período autárquico - de mantener altos niveles de rentabilidad, y el efecto depresor sobre la cuenta de resultados de las empresas españolas provocado por la competencia que éstas debieron afrontar a raíz de la relativa liberalización de las importaciones que siguió al Plan de Estabilización. Está claro que esta cuestión reclama un análisis más concienzudo, y debo admitir que cuando se lleve a cabo quizás habrá que recomponer la imagen de la trayectoria de los beneficios en el decenio de $1960^{30}$.

${ }^{30}$ No es, empero, seguro que así sea. Manuel Román, en un análisis coetáneo a la existencia del fenómeno (1967) constató una fuerte reducción de la tasa de rentabilidad, que atribuyó a diversos factores (incremento de los salarios reales, deterioro de la relación capital-producto, concurrencia de los productos importados). Según sus cálculos, la tasa media de beneficios en relación con el capital disminuyó entre 1961 y 1966 en una proporción exactamente equivalente a la que se obtiene dividiendo el agregado que he estimado por los recursos propios. Véase Román (1972), pp. 100-102 y 187. 


\section{LOS BENEFICIOS Y LAS PRINCIPALES MACROMAGNITUDES ECONÓMICAS}

El agregado de los excedentes de las empresas constituye una macromagnitud fundamental en cualquier economía capitalista plenamente desarrollada o en vías de desarrollo. Lo es porque el excedente empresarial influye poderosamente sobre la inversión, el empleo y la marcha de la actividad económica en su conjunto ${ }^{31}$. Sin él no existe acumulación de capital privado en los sectores productivos, que es la fuente primordial del progreso económico. Por consiguiente, al presentar una estimación sobre dicha variable es obligado confrontarla con, al menos, las series históricas de tres macromagnitudes básicas, la renta o producto interior, la formación de capital y la producción industrial. En el cuadro 5 se compara el crecimiento de las cuatro macromagnitudes indicadas, con arreglo a una periodización ampliamente aceptada.

\section{CUADRO 5}

Tasas de crecimiento anual de los beneficios, la producción industrial, el producto interior y la formación de capital

\begin{tabular}{|c|c|c|c|c|}
\hline & Beneficios & IPIES & PIB & $F B C F$ \\
\hline $1880-1891 \ldots \ldots \ldots \ldots \ldots$ & 1,95 & 2,23 & 0,65 & 1,77 \\
\hline $1891-1913 \ldots \ldots \ldots \ldots \ldots$ & 5,13 & 2,16 & 1,42 & 4,33 \\
\hline $1913-1929 \ldots \ldots \ldots \ldots . . .$. & 2,85 & 2,91 & 2,68 & 4,30 \\
\hline $1929-1950 \ldots \ldots \ldots \ldots \ldots$ & 1,21 & 0,31 & 1,07 & $-1,16$ \\
\hline $1950-1973 \ldots \ldots \ldots \ldots \ldots$ & 8,31 & 8,50 & 6,51 & 8,36 \\
\hline $1973-1981 \ldots \ldots \ldots \ldots$ & $-2,09$ & 2,17 & 3,12 & 1,20 \\
\hline $1880-1981 \ldots \ldots \ldots \ldots$ & 3,71 & 3,31 & 2,53 & 3,52 \\
\hline
\end{tabular}

FuENTES: IPIES, Carreras (1984); PIB, Prados (1995, tabla B.8); FBCF, elaboración propia a partir de Carreras (1985) y Prados (1995); véase nota 33 .

El contraste entre la primera serie y las restantes no puede ser más aleccionador. En el conjunto del siglo (1880-1981), los resultados de las grandes empresas han crecido más que los otros agregados económicos. Es extremadamente interesante notar que el mayor dinamismo del

${ }^{31}$ Sobre los canales y el alcance del impacto macroeconómico, a corto y largo plazo, de los beneficios, véase, por ejemplo, Duménil y Lévy (1993). 
excedente empresarial es bastante acusado con respecto al PIB, pero no lo es en relación a la producción industrial, y, menos aún, a la inversión. Entre ésta y los beneficios hay una concordancia básica en la tendencia secular. Que la evolución de los mismos sintonizó con los ritmos de crecimiento a largo plazo de la economía, la industria y la inversión agregada es algo que se desprende, de forma incontrovertible, de los valores del cuadro, como también lo es que tal sintonía fue de menor a mayor grado por el orden en que han sido enunciadas las macromagnitudes.

En efecto, el cuadro revela algunas discrepancias, no demasiado trascendentales, en general, entre el movimiento del PIB y de los beneficios durante las primeras etapas y en los últimos años. Mientras que a lo largo de los diversos períodos en que se divide el medio siglo inicial se produjo una progresiva aceleración económica, los beneficios tuvieron un comportamiento irregular - fuerte expansión en 1891-1913, crecimiento moderado durante 1913-1929, aunque sensiblemente superior al registrado en 1880-1891--. La divergencia entre las dos series en el período final es mucho más llamativa, o quizás sería mejor decir más aparente. Comparando el nivel de 1981 con el de 1973, el PIB creció a una tasa apreciable, en tanto que los beneficios sufrieron una caída continuada e intensa a partir de 1973. Pero el aumento del producto total es un hecho más bien engañoso, pues, como es harto conocido, para la economía española la época dorada se prolongó algo más y tuvo en 1976-77 una efímera reactivación, viéndose abocada desde entonces hasta 1984 a un estado de persistente estancamiento. Las divergencias observadas se repiten, notablemente atenuadas, entre las series de los beneficios y la producción industrial. Pero tal vez sea más relevador lo ocurrido en los períodos 1929-1950 y 1950-1973. Las tasas de crecimiento en el segundo de ellos son extraordinariamente parejas. En cuanto al primero, se detecta con claridad que el casi completo estancamiento industrial no tuvo fiel reflejo en los beneficios. En aquellos años coexiste una situación de depresión industrial con un crecimiento de los beneficios, que, si bien es menor que el de cualquier otra etapa, exhibe un singular divorcio entre ambas variables. Nuevamente, esto nos evoca la formación de beneficios extraordinarios durante la autarquía. La atonía del sistema productivo no fue ningún impedimiento para la obtención de elevados excedentes. Al contrario, los mismos factores que ocasionaban lo primero - cupos y licencias de importación, tasación de productos, autorización de nuevas inversiones, etc. - tenían el efecto perverso de acrecentar desmesuradamente los márgenes de las empresas instaladas. 
La confrontación entre las tasas de crecimiento de los beneficios y de la formación de capital es aún más sugestiva. Los paralelismos son la regla, y los desacuerdos, a fuer de excepcionales, encierran una especial significación. Repárese en que el imponente ascenso de mi serie en 1891-1913, que, a tenor del curso seguido por el PIB y el IPIES, parecía exagerar considerablemente la evolución real experimentada por los excedentes empresariales, guarda una clara afinidad con el comportamiento de la inversión. El boom de las rentas empresariales fue de una envergadura algo mayor que el auge inversor, pero en la etapa siguiente sucedió lo contrario. De modo que beneficios e inversión crecieron a tasas muy similares durante el período 1891-1929, tomado en su globalidad ${ }^{32}$. En el ulterior período largo expansivo (1950-1973) los ritmos de crecimiento fueron, de nuevo, casi matemáticamente coincidentes. En años de débiles avances (1880-1891), ambas macromagnitudes también aumentaron a una velocidad semejante. En cambio, en los tiempos caracterizados por persistentes depresiones (1929-1950, 1973-1981), se produjeron significativas diferencias. La retracción inversora ocurrida en el primero de ellos refuerza el diagnóstico antes expuesto de lo anómalo del aumento de los beneficios. Por lo que se refiere a la divergencia de los años 1973-1981, cabe señalar que, aun siendo significativa - los beneficios agregados se contraen sensiblemente, mientras la formación de capital continúa incrementándose levemente-, la trayectoria de mi serie está más próxima a la de la inversión que a los restantes agregados económicos. En definitiva, el parentesco entre beneficios e inversión es tan grande que está justificado que analicemos con más atención el movimiento de las dos series.

El anexo 2 ofrece el detalle de las cifras anuales estimadas de la formación de capital fijo y de los beneficios, en valores corrientes ${ }^{33}$. Los gráficos 7 y 8 ilustran la evolución de ambas series, tras haber convertido los valores a números índices tomando como períodos base los años 1930 y 1950 , respectivamente ${ }^{34}$.

Los mencionados gráficos son impactantes. Salta a la vista que los movimientos de los beneficios han estado muy correlacionados con los de la inversión, tanto a largo plazo como a corto. No se trata sólo de

324,17 por 100 anual y 4,31 por 100 , respectivamente.

${ }_{33}$ Para calcular las cifras de la formación de capital he recalculado previamente las tasas de inversión obtenidas por Carreras (1985). Véase Tafunell (1996), pp. 42-3.

${ }^{34}$ He dividido las series en dos tramos, cortándolas en el paréntesis de la Guerra Civil, a fin de que puedan apreciarse mejor los paralelismos y los desencuentros de las curvas. Un gráfico que contenga las series completas aplana el perfil de las primeras décadas. Creo que la alternativa que he tomado es preferible a la de deflactar las series. 


\section{GRÁFICO 7}

Beneficios e inversión, en pesetas corrientes $(1930=100)$

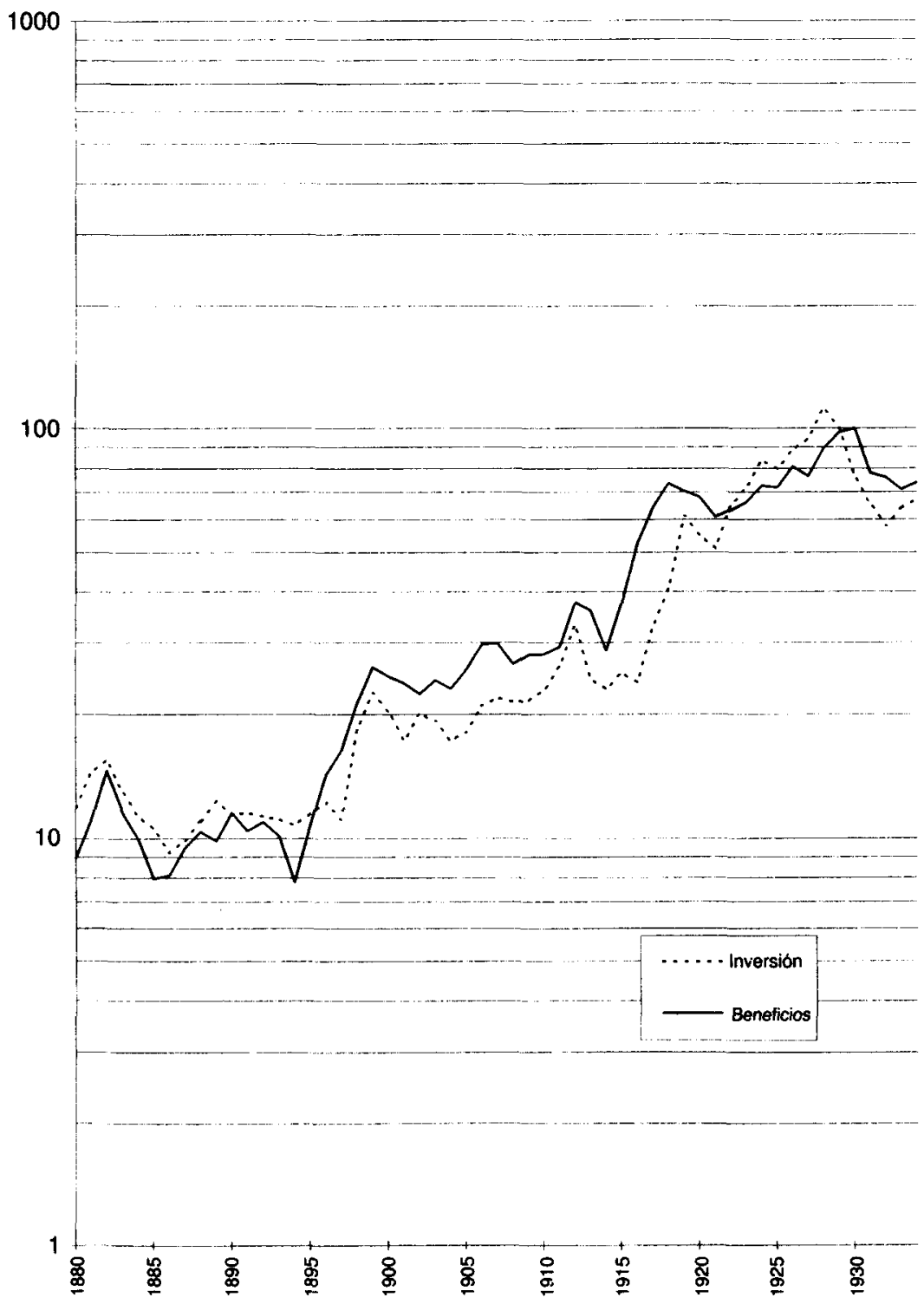




\section{GRÁFICO 8}

Beneficios e inversión, en pesetas corrientes $(1950=100)$

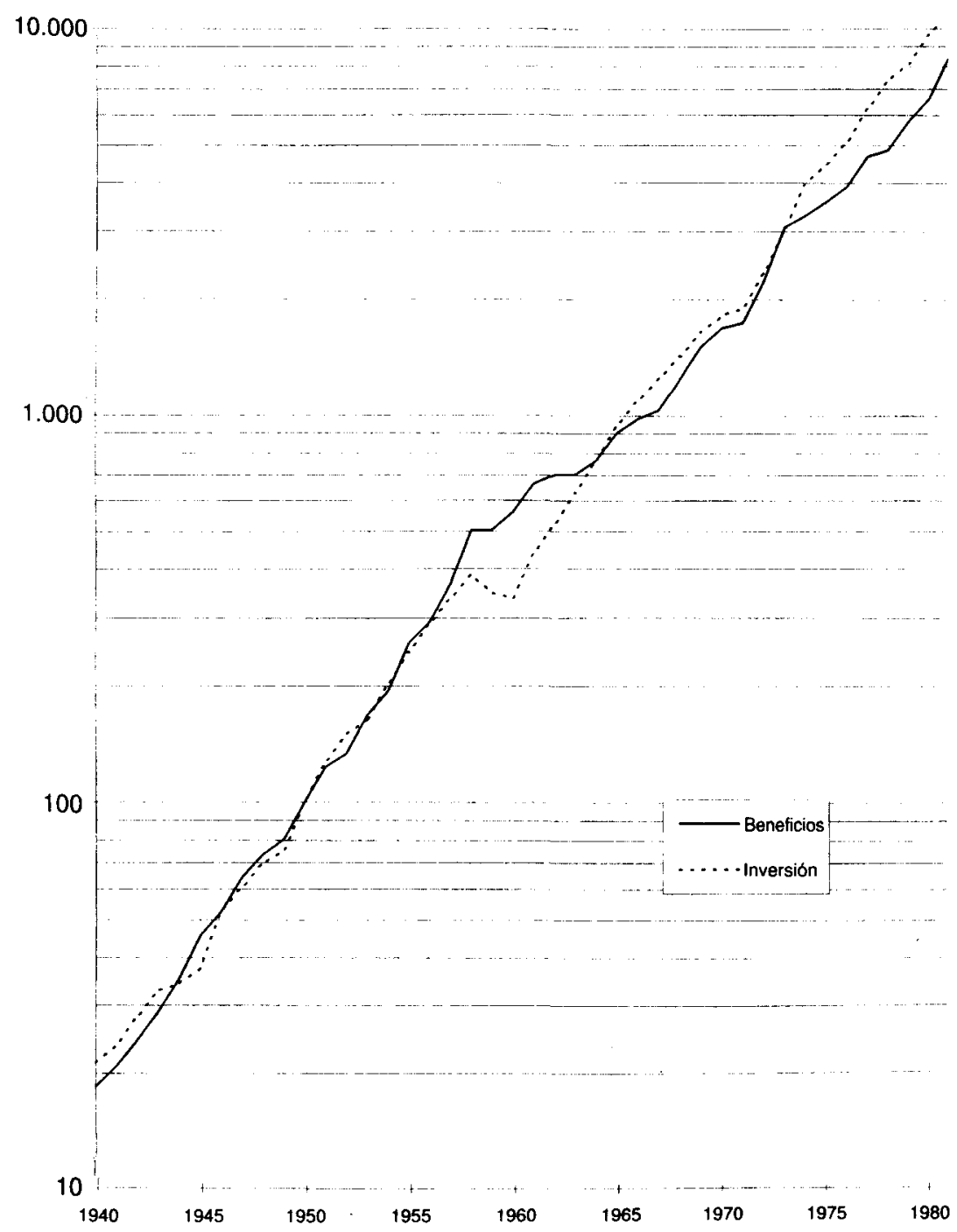

que la tendencia secular de ambas magnitudes sea prácticamente idéntica. Comparten todas las grandes fluctuaciones cíclicas. En una y otra variable 
éstas tienen la misma, o muy parecida, cronología, y también tienen, en general, similar amplitud. Si tenemos en cuenta que se trata de dos indicadores de distinta naturaleza que han sido estimados por procedimientos completamente independientes, la semejanza entre ambas series debe calificarse como extraordinaria. Entre otras cosas, refuerza su consistencia.

Es particularmente interesante notar que la serie de beneficios tiende a anticiparse ligeramente - un año- a la de inversión. Este leve desfase está lleno de sentido. Sugiere que los excedentes empresariales han sido un determinante básico de la formación de capital. Tal evidencia está en consonancia con el análisis económico y el histórico: la inversión se nutre en buena medida de la autofinanciación y depende críticamente de las expectativas de beneficios futuros, las cuales están influidas por el nivel de los que se han logrado en el inmediato pasado.

Es difícil exagerar la extraordinaria semejanza en la evolución cursada por los beneficios y la inversión. Pero también resulta interesante no perder de vista que en ciertas coyunturas no han marchado al compás. Las ocasionales discordancias también nos ayudan a entender cuán estrechos eran los ligámenes entre ambas variables. Fijémonos, por ejemplo, en el desajuste, aparentemente aparatoso, del último lustro del siglo. El auge finisecular se inicia en 1895 en lo que se refiere a los beneficios, mientras que no llega hasta 1899 en la inversión. Las perturbaciones ocasionadas por la guerra de Cuba quizás provocaron el retraso en la respuesta inversora. Ahora bien, cuando llegó fue casi tan potente como el salto dado por los resultados de las empresas. Otro desajuste sobresaliente es el que tuvo lugar durante los años de la Gran Guerra. De 1915 a 1918 se registra una explosión de beneficios; mientras, la formación de capital se mantiene estancada, debido a las dificultades para importar bienes de equipo. Pero, al igual que sucediera en el último lustro de la centuria anterior, la inversión acaba reproduciendo el ascenso vivido por los excedentes empresariales. De manera que ambas series conforman el mismo perfil cíclico con un notable retraso en la fase expansiva - no así en la descendente- por parte de la segunda variable. Una tercera diferencia destacable se encuentra en el crecimiento de los años veinte. En esta ocasión no hubo desfase temporal, e incluso parece bastante claro que la inversión fue por delante de los beneficios, $\mathrm{y}$, además, se expandió a un ritmo mucho más vivo. Una explicación hipotética de tan peculiar fenómeno podría consistir en que el sensacional auge inversor de la década de 1920 se financió en parte con los beneficios acumulados durante el conflicto europeo. 
En el segundo tramo de las series (véase gráfico 8) es, en general, aún más díficil descubrir divergencias en su evolución dignas de ser subrayadas. Es cierto que las tasas de crecimiento exponenciales, añadidas a la intensa inflación, tienden a aplastar las fluctuaciones a corto plazo, $y$, en consecuencia, a anular las discrepancias que puedan haberse producido en el curso de los ciclos. Sin embargo, si examinamos con atención el gráfico comprobaremos que sigue siendo válido lo afirmado para el primer tramo: coincidencia básica en la cronología, ligera anticipación de los beneficios, estrecho paralelismo en el perfil de las curvas. La única disconformidad verdaderamente importante es la acaecida en los años sesenta, más concretamente entre 1961 y 1967 . Durante este período la inversión mostró un dinamismo mucho mayor que los excedentes, con lo cual abundamos en la perplejidad que nos provocaba observar la pérdida de ritmo de éstos en un contexto de fortísima expansión económica.

\section{CONCLUSIONES}

La elaboración del índice aquí publicado obliga a replantearse algunas ideas aceptadas desde hace largo tiempo por los historiadores económicos. En primer lugar, arrumba el mito de la imposibilidad de poder llevar a cabo una cuantificación mínimamente fidedigna sobre la evolución histórica de los excedentes empresariales basándose en los datos contables publicados por las propias sociedades. En segundo lugar, y ligado a lo anterior, demuestra que el investigador que se propone reconstruir estadísticamente un agregado de esta naturaleza no arrostra el riesgo de una búsqueda interminable de información adecuada. De esto no se sigue, en absoluto, que la serie presentada se haga acreedora de los mayores parabienes por parte de aquellos que estudian la evolución macroeconómica de España en el último siglo. Como suele suceder en las primeras estimaciones de una macromagnitud, las cifras que se dan a conocer en este ensayo tienen un carácter provisional. Admiten ser revisadas en profundidad, e incluso invitan a ello. Porque si, por una parte, con ellas refrendamos algunas interpretaciones establecidas por la historiografía, o descubrimos las alternativas de expansión y contracción que, plausiblemente, siguieron los recursos generados por las empresas, por otra parte, el curso que describe el índice plantea nuevos interrogantes, y no despeja del todo las dudas que cabe albergar sobre su solidez, cuando menos en lo que concierne a algunas coyunturas concretas. En las páginas 
que anteceden no he rehuido el reconocimiento de esos puntos negros. El auge del último lustro del siglo XIX y, sobre todo, el estancamiento del período comprendido entre 1961 y 1967 son, a mi entender, objeto de sospecha. Asimismo, habría que revisar la cuantificación para los años 1935-39. En otro orden de cosas, genérico, no tendriamos que perder de vista en ningún momento las dos limitaciones mayores del trabajo: una, debida al tipo de empresa estudiado, y otra, a la categoría de excedente que ha sido objeto de medición. Mi universo de análisis es la gran empresa constituida en régimen jurídico de sociedad anónima, y eso indudablemente hace problemáticas las interpretaciones generalizadoras, refiriéndose a una realidad en que las pequeñas y medianas empresas han tenido un peso abrumador. En segundo lugar, mi reconstrucción estadística no llega a determinar la magnitud del beneficio económico, sino un concepto próximo a él, denominado «recursos generados». Desde la perspectiva de la contabilidad nacional histórica, la aproximación realizada resulta a todas luces insuficiente. Cifrar el beneficio económico, y, asimismo, la rentabilidad, pasa a ser una tarea inaplazable.

Pero si es cierto que el presente ensayo cuantitativo adolece de debilidades manifiestas también lo es que puede exhibir cualidades que lo convierten en un instrumento útil, siquiera sea mientras continúe siendo tan precario nuestro conocimiento sobre el curso histórico de los excedentes empresariales. El índice aquí presentado supera airosamente la comparación con las elaboraciones precedentes, particularmente con aquellas que tienen una calidad reconocida. La tendencia a largo plazo de mi serie viene a ser la misma que la trazada por los agregados del excedente, en términos de contabilidad nacional, estimados por el Instituto Nacional de Estadística y el Servicio de Estudios del Banco de Bilbao. En las inflexiones cíclicas y las fluctuaciones de más corto plazo también se repite el paralelismo, aunque se advierten algunas diferencias en cuanto a la intensidad de las variaciones. Esto puede hacerse extensivo, con algunos matices, a los contadísimos índices de beneficios confeccionados para períodos anteriores. Aunque no ha sido posible determinar el origen de las discrepancias observadas, resulta manifiesto que el nuevo índice aventaja a los anteriores por su carácter de serie histórica homogénea y larga.

El índice desvela la existencia y alternancia de movimientos a largo plazo. El primero de ellos, de signo ascendente, dio comienzo en 1895 y finalizó en 1930. El segundo, de carácter opuesto, abarcó de $1930^{\circ}$ a 1950. En el tercero, comprendido entre 1951 y 1973, se asistió a una nueva escalada, más vigorosa, y, asimismo, más irregular, que en la fase expansiva 
del inicio de siglo. Desde 1973 se entró en una etapa contractiva, cuyo final se sitúa más allá del término de la serie.

Las cifras muestran, asimismo, que los beneficios no marcharon linealmente por la senda, ora ascendente, ora descendente, marcada por las tendencias a largo plazo. Se apartaron grandemente de ellas, fluctuando intensamente. Estas oscilaciones a corto plazo no son en absoluto erráticas. El curso de los beneficios dibuja unos movimientos cíclicos perfectamente definidos, aunque irregulares en duración y amplitud. Se adivina que ha habido una clara relación entre la dinámica de los beneficios y el ciclo económico.

Un análisis superficial de los ritmos de crecimiento, en grandes períodos, de los beneficios y de algunas macromagnitudes básicas pone de relieve que los primeros progresaron, generalmente, al compás del avance del producto total, la producción industrial y la inversión. De una primera lectura de los datos se desprende que la marcha de los beneficios estuvo más correlacionada con la del sector industrial que con la de la economía en su conjunto, y que la correlación fue muy estrecha con la evolución de la formación de capital. La evidencia aportada en este sentido es, probablemente, lo más sobresaliente del presente ensayo. 


\section{ANEXO 1}

Indice de los beneficios agregados $(1950=100)$

\begin{tabular}{|c|c|c|c|c|c|}
\hline$A \overline{n o}$ & Nominales $^{1}$ & Reales $^{2}$ & Año & Nominales $^{1}$ & Reales $^{2}$ \\
\hline $1880 \ldots \ldots \ldots \ldots$ & 1,35 & 13,30 & $1931 \ldots \ldots \ldots . . . . .$. & 11,76 & 62,90 \\
\hline $1881 \ldots \ldots \ldots \ldots$ & 1,66 & 15,52 & $1932 \ldots \ldots \ldots \ldots$ & 11,48 & 61,86 \\
\hline $1882 \ldots \ldots \ldots \ldots$ & 2,20 & 19,74 & $1933 \ldots \ldots \ldots . . . . .$. & 10,70 & 62,05 \\
\hline $1883 \ldots \ldots \ldots \ldots$ & 1,75 & 15,90 & $1934 \ldots \ldots \ldots \ldots$ & 11,12 & 61,89 \\
\hline $1884 \ldots \ldots \ldots \ldots$ & 1,51 & 14,45 & $1935 \ldots \ldots \ldots \ldots$ & 12,55 & 70,38 \\
\hline $1885 \ldots \ldots \ldots$ & 1,20 & 11,51 & $1936 \ldots \ldots \ldots \ldots$ & 7,65 & 44,76 \\
\hline $1886 \ldots \ldots \ldots \ldots$ & 1,22 & 11,73 & $1937 \ldots \ldots \ldots \ldots$ & 7,67 & 39,51 \\
\hline $1887 \ldots \ldots \ldots \ldots$ & 1,44 & 14,33 & $1938 \ldots \ldots \ldots . . .$. & 11,52 & 52,28 \\
\hline $1888 \ldots \ldots \ldots \ldots$ & 1,57 & 15,66 & $1939 \ldots \ldots \ldots \ldots$ & 13,26 & 51,69 \\
\hline $1889 \ldots \ldots \ldots \ldots$ & 1,49 & 15,77 & $1940 \ldots \ldots \ldots \ldots$ & 18,44 & 59,20 \\
\hline $1890 \ldots \ldots \ldots \ldots$ & 1,74 & 18,44 & $1941 \ldots \ldots \ldots \ldots$ & 21,00 & 56,84 \\
\hline $1891 \ldots \ldots \ldots \ldots$ & 1,57 & 16,46 & $1942 \ldots \ldots \ldots \ldots$ & 24,45 & 59,20 \\
\hline $1892 \ldots \ldots \ldots \ldots$ & 1,65 & 17,55 & $1943 \ldots \ldots \ldots \ldots$ & 28,97 & 66,86 \\
\hline $1893 \ldots \ldots \ldots . . .$. & 1,53 & 15,78 & $1944 \ldots \ldots \ldots \ldots$ & 35,46 & 71,97 \\
\hline $1894 \ldots \ldots \ldots \ldots$ & 1,18 & 12,71 & $1945 \ldots \ldots \ldots \ldots$ & 45,57 & 86,86 \\
\hline $1895 \ldots \ldots \ldots \ldots$ & 1,62 & 17,22 & $1946 \ldots \ldots \ldots \ldots$ & 52,71 & 82,29 \\
\hline $1896 \ldots \ldots \ldots \ldots$ & 2,16 & 22,55 & $1947 \ldots \ldots \ldots \ldots$ & 64,31 & 90,93 \\
\hline $1897 \ldots \ldots \ldots . . . . . .$. & 2,48 & 24,79 & $1948 \ldots \ldots \ldots \ldots$ & 73,58 & 98,01 \\
\hline $1898 \ldots \ldots \ldots \ldots$ & 3,23 & 30,53 & $1949 \ldots \ldots \ldots \ldots$ & 80,71 & 98,56 \\
\hline $1899 \ldots \ldots \ldots \ldots$ & 3,95 & 38,91 & $1950 \ldots \ldots \ldots \ldots$ & 100,00 & 100,00 \\
\hline $1900 \ldots \ldots \ldots \ldots$ & 3,75 & 35,42 & $1951 \ldots \ldots \ldots \ldots$ & 123,70 & 100,30 \\
\hline $1901 \ldots \ldots \ldots \ldots$ & 3,61 & 34,10 & $1952 \ldots \ldots \ldots . . .$. & 133,83 & 108,13 \\
\hline $1902 \ldots \ldots \ldots \ldots$ & 3,40 & 32,59 & $1953 \ldots \ldots \ldots \ldots$ & 167,85 & 130,28 \\
\hline $1903 \ldots \ldots \ldots \ldots$ & 3,67 & 33,32 & $1954 \ldots \ldots \ldots \ldots$ & 194,57 & 142,97 \\
\hline $1904 \ldots \ldots \ldots \ldots$ & 3,50 & 31,36 & $1955 \ldots \ldots \ldots \ldots$ & 258,22 & 179,61 \\
\hline $1905 \ldots \ldots \ldots \ldots$ & 3,89 & 34,86 & $1956 \ldots \ldots \ldots \ldots$ & 293,84 & 190,19 \\
\hline $1906 \ldots \ldots \ldots \ldots$ & 4,47 & 41,67 & $1957 \ldots \ldots \ldots \ldots$ & 366,75 & 210,36 \\
\hline $1907 \ldots \ldots \ldots . . . .$. & 4,51 & 38,92 & $1958 \ldots \ldots \ldots \ldots$ & 504,18 & 259,42 \\
\hline $1908 \ldots \ldots \ldots \ldots$ & 4,02 & 36,96 & $1959 \ldots \ldots \ldots \ldots$ & 505,07 & 243,20 \\
\hline $1909 \ldots \ldots \ldots . . . .$. & 4,22 & 38,84 & $1960 \ldots \ldots \ldots \ldots$ & 560,87 & 268,01 \\
\hline $1910 \ldots \ldots \ldots \ldots$ & 4,24 & 40,08 & $1961 \ldots \ldots \ldots$ & 663,42 & 311,62 \\
\hline $1911 \ldots \ldots \ldots \ldots$ & 4,42 & 41,76 & $1962 \ldots \ldots \ldots \ldots$ & 701,67 & 312,58 \\
\hline $1912 \ldots \ldots \ldots \ldots$ & 5,69 & 53,76 & $1963 \ldots \ldots \ldots \ldots$ & 703,72 & 287,15 \\
\hline $1913 \ldots \ldots \ldots \ldots$ & 5,45 & 49,53 & $1964 \ldots \ldots \ldots \ldots$ & 767,11 & 297,03 \\
\hline $1914 \ldots \ldots \ldots \ldots . . .$. & 4,32 & 39,77 & $1965 \ldots \ldots \ldots \ldots$ & 904,73 & 318,67 \\
\hline $1915 \ldots \ldots \ldots \ldots$ & 5,69 & 45,63 & $1966 \ldots \ldots \ldots . . . .$. & 981,21 & 320,57 \\
\hline
\end{tabular}




\begin{tabular}{|c|c|c|c|c|c|}
\hline Año & Nominales ${ }^{1}$ & Reales $^{2}$ & Año & Nominales ${ }^{1}$ & Reales $^{2}$ \\
\hline $1916 \ldots \ldots \ldots$ & 7,96 & 56,60 & $1967 .$. & $1.033,29$ & 318,72 \\
\hline $1917 \ldots \ldots \ldots \ldots$ & 9,68 & 63,01 & $1968 \ldots \ldots \ldots \ldots$ & $1.246,80$ & 368,12 \\
\hline $1918 \ldots \ldots \ldots \ldots$ & 11,09 & 57,52 & $1969 \ldots \ldots \ldots \ldots$ & $1.510,53$ & 429,09 \\
\hline $1919 \ldots \ldots \ldots \ldots$ & 10,62 & 50,89 & $1970 \ldots \ldots \ldots \ldots$ & $1.686,07$ & 451,80 \\
\hline $1920 \ldots \ldots \ldots \ldots$ & 10,27 & 44,84 & $1971 \ldots \ldots \ldots \ldots$ & $1.740,73$ & 432,52 \\
\hline $1921 \ldots \ldots \ldots \ldots$ & 9,19 & 47,66 & $1972 \ldots \ldots \ldots \ldots$ & $2.229,26$ & 509,17 \\
\hline $1922 \ldots \ldots \ldots \ldots$ & 9,53 & 50,21 & $1973 \ldots \ldots \ldots \ldots$ & $3.077,01$ & 626,85 \\
\hline $1923 \ldots \ldots \ldots \ldots$ & 9,95 & 53,21 & $1974 \ldots \ldots \ldots \ldots$ & $3.289,94$ & 579,99 \\
\hline $1924 \ldots \ldots \ldots \ldots$ & 10,94 & 55,49 & $1975 \ldots \ldots \ldots \ldots$ & $3.566,30$ & 547,56 \\
\hline $1925 \ldots \ldots \ldots \ldots$ & 10,84 & 53,43 & $1976 \ldots \ldots \ldots \ldots$ & $3.904,16$ & 517,95 \\
\hline $1926 \ldots \ldots \ldots \ldots$ & 12,21 & 63,84 & $1977 \ldots \ldots \ldots \ldots$ & $4.675,33$ & 508,11 \\
\hline $1927 \ldots \ldots \ldots \ldots$ & 11,55 & 59,94 & $1978 \ldots \ldots \ldots \ldots$ & $4.863,20$ & 446,76 \\
\hline $1928 \ldots \ldots \ldots \ldots$ & 13,48 & 73,85 & $1979 \ldots \ldots \ldots \ldots$ & $5.791,21$ & 456,52 \\
\hline $1929 \ldots \ldots \ldots \ldots$ & 14,75 & 77,69 & $1980 \ldots \ldots \ldots \ldots$ & $6.626,89$ & 457,26 \\
\hline $1930 \ldots \ldots \ldots . . . .$. & 15,08 & 80,06 & $1981 \ldots \ldots \ldots \ldots$ & $8.590,78$ & 529,35 \\
\hline
\end{tabular}

${ }^{1}$ En pesetas corrientes.

2 En pesetas constantes de 1950, utilizando el deflactor del PIB de Prados (1995), tabla D.3, pp. 175-178.

ANEXO 2

Índice de beneficios y formación de capital, en pesetas corrientes $(1930=100)$

\begin{tabular}{|c|c|c|c|c|c|}
\hline Año & Beneficios & $F B C F$ & Año & Beneficios & $F B C F$ \\
\hline $1880 \ldots \ldots \ldots \ldots$ & 8,9 & 9,9 & $1931 \ldots \ldots \ldots \ldots$ & 78,0 & 76,5 \\
\hline $1881 \ldots \ldots \ldots \ldots$ & 11,0 & 11,8 & $1932 \ldots \ldots \ldots \ldots$ & 76,1 & 65,3 \\
\hline $1882 \ldots \ldots \ldots \ldots$ & 14,6 & 14,3 & $1933 \ldots \ldots \ldots \ldots$ & 70,9 & 58,2 \\
\hline $1883 \ldots \ldots \ldots \ldots$ & 11,6 & 15,4 & $1934 \ldots \ldots \ldots \ldots$ & 73,7 & 63,6 \\
\hline $1884 \ldots \ldots \ldots \ldots$ & 10,0 & 12,8 & $1935 \ldots \ldots \ldots \ldots$ & 83,2 & 67,3 \\
\hline $1885 \ldots \ldots \ldots \ldots$ & 8,0 & 11,3 & $1936 \ldots \ldots \ldots \ldots$ & 50,7 & - \\
\hline $1886 \ldots \ldots \ldots \ldots$ & 8,1 & 10,5 & $1937 \ldots \ldots \ldots \ldots$ & 50,9 & 一 \\
\hline $1887 \ldots \ldots \ldots \ldots$ & 9,5 & 9,2 & $1938 \ldots \ldots \ldots \ldots$ & 76,4 & - \\
\hline $1888 \ldots \ldots \ldots \ldots$ & 10,4 & 9,8 & $1939 \ldots \ldots \ldots \ldots$ & 87,9 & 一 \\
\hline $1889 \ldots \ldots \ldots \ldots$ & 9,8 & 11,0 & $1940 \ldots \ldots \ldots \ldots$ & 122,3 & 97,3 \\
\hline $1890 \ldots \ldots \ldots \ldots$ & 11,5 & 12,3 & $1941 \ldots \ldots \ldots \ldots$ & 139,3 & 110,2 \\
\hline $1891 \ldots \ldots \ldots \ldots$ & 10,4 & 11,4 & $1942 \ldots \ldots \ldots \ldots$ & 162,1 & 130,9 \\
\hline $1892 \ldots \ldots \ldots \ldots$ & 11,0 & 11,5 & $1943 \ldots \ldots \ldots \ldots$ & 192,1 & 155,1 \\
\hline
\end{tabular}




\begin{tabular}{|c|c|c|c|c|c|}
\hline Año & Beneficios & $F B C F$ & $A \tilde{n} o$ & Beneficios & $F B C F$ \\
\hline $1893 \ldots \ldots \ldots \ldots$ & 10,2 & 11,3 & $1944 \ldots \ldots \ldots \ldots$ & 235,1 & 160,9 \\
\hline $1894 \ldots \ldots \ldots \ldots$ & 7,8 & 11,1 & $1945 \ldots \ldots \ldots \ldots$ & 302,1 & 175,0 \\
\hline $1895 \ldots \ldots \ldots \ldots$ & 10,8 & 10,7 & $1946 \ldots \ldots \ldots \ldots$ & 349,5 & 245,3 \\
\hline $1896 \ldots \ldots \ldots \ldots$ & 14,3 & 11,5 & $1947 \ldots$. & 426,4 & 282,1 \\
\hline $1897 \ldots \ldots \ldots \ldots$ & 16,4 & 12,1 & $1948 \ldots \ldots \ldots \ldots$ & 487,8 & 325,6 \\
\hline $1898 \ldots \ldots \ldots \ldots$ & 21,4 & 11,1 & $1949 \ldots \ldots \ldots \ldots$ & 535,1 & 353,3 \\
\hline $1899 \ldots \ldots \ldots \ldots$ & 26,2 & 18,5 & $1950 \ldots \ldots \ldots$ & 663,0 & 463,7 \\
\hline $1900 \ldots \ldots \ldots \ldots$ & 24,8 & 22,6 & $1951 \ldots \ldots \ldots \ldots$ & 820,1 & 589,6 \\
\hline $1901 \ldots \ldots \ldots \ldots$ & 23,9 & 20,3 & $1952 \ldots \ldots \ldots \ldots$ & 887,3 & 694,4 \\
\hline $1902 \ldots \ldots \ldots \ldots$ & 22,5 & 17,2 & $1953 \ldots \ldots \ldots \ldots$ & $1.112,8$ & 762,0 \\
\hline $1903 \ldots \ldots \ldots \ldots$ & 24,3 & 20,0 & $1954 \ldots \ldots \ldots \ldots$ & $1.290,0$ & 952,7 \\
\hline $1904 \ldots \ldots \ldots \ldots$ & 23,2 & 19,2 & $1955 \ldots \ldots \ldots \ldots$ & $1.712,0$ & $1.148,9$ \\
\hline $1905 \ldots \ldots \ldots \ldots$ & 25,8 & 17,2 & $1956 \ldots \ldots \ldots \ldots$ & $1.948,1$ & $1.372,4$ \\
\hline $1906 \ldots \ldots \ldots \ldots . . . .$. & 29,6 & 18,2 & $1957 \ldots \ldots \ldots \ldots$ & $2.431,5$ & $1.593,6$ \\
\hline $1907 \ldots \ldots \ldots \ldots$ & 29,9 & 20,9 & $1958 \ldots \ldots \ldots \ldots$ & $3.342,6$ & $1.814,5$ \\
\hline $1908 \ldots \ldots \ldots \ldots$ & 26,6 & 22,0 & $1959 \ldots \ldots \ldots . . . . .$. & $3.348,5$ & $1.641,4$ \\
\hline $1909 \ldots \ldots \ldots \ldots$ & 28,0 & 21,4 & $1960 \ldots \ldots \ldots \ldots$ & $3.718,5$ & $1.599,7$ \\
\hline $1910 \ldots \ldots \ldots \ldots$ & 28,1 & 21,7 & $1961 \ldots \ldots \ldots \ldots$ & $4.398,4$ & $2.084,5$ \\
\hline $1911 \ldots \ldots \ldots \ldots$ & 29,3 & 23,0 & $1962 \ldots \ldots \ldots \ldots$ & $4.652,0$ & $2.472,3$ \\
\hline $1912 \ldots \ldots \ldots \ldots . . .$. & 37,7 & 26,1 & $1963 \ldots \ldots \ldots \ldots$ & $4.665,6$ & $2.978,9$ \\
\hline $1913 \ldots \ldots \ldots \ldots$ & 36,2 & 33,3 & $1964 \ldots \ldots \ldots \ldots$ & $5.085,9$ & $3.645,0$ \\
\hline $1914 \ldots \ldots \ldots \ldots . .$. & 28,7 & 24,5 & $1965 \ldots \ldots \ldots \ldots$ & $5.998,3$ & $4.486,5$ \\
\hline $1915 \ldots \ldots \ldots \ldots$ & 37,7 & 22,8 & $1966 \ldots \ldots \ldots \ldots$ & $6.505,3$ & $5.246,0$ \\
\hline $1916 \ldots \ldots \ldots \ldots$ & 52,8 & 24,9 & $1967 \ldots \ldots \ldots \ldots$ & $6.850,6$ & $5.951,3$ \\
\hline $1917 \ldots \ldots \ldots \ldots$ & 64,2 & 23,6 & $1968 \ldots \ldots \ldots \ldots$ & $8.266,1$ & $6.767,0$ \\
\hline $1918 \ldots \ldots \ldots \ldots$ & 73,5 & 32,0 & $1969 \ldots \ldots \ldots \ldots$ & $10.014,6$ & $7.855,6$ \\
\hline $1919 \ldots \ldots \ldots \ldots$ & 70,4 & 40,2 & $1970 \ldots \ldots \ldots \ldots$ & $11.178,4$ & $8.692,0$ \\
\hline $1920 \ldots \ldots \ldots \ldots$ & 68,1 & 60,3 & $1971 \ldots \ldots \ldots \ldots$ & $11.540,8$ & $9.043,8$ \\
\hline $1921 \ldots \ldots \ldots \ldots$ & 60,9 & 55,2 & $1972 \ldots \ldots \ldots \ldots$ & $14.779,7$ & $11.141,0$ \\
\hline $1922 \ldots \ldots \ldots \ldots$ & 63,2 & 51,0 & $1973 \ldots \ldots \ldots \ldots$ & $20.400,1$ & $14.421,8$ \\
\hline $1923 \ldots \ldots \ldots \ldots$ & 66,0 & 64,7 & $1974 \ldots \ldots \ldots \ldots$ & $21.811,9$ & $18.725,8$ \\
\hline $1924 \ldots \ldots \ldots \ldots$ & 72,5 & 72,2 & $1975 \ldots \ldots \ldots \ldots$ & $23.644,1$ & $20.918,8$ \\
\hline $1925 \ldots \ldots \ldots \ldots$ & 71,9 & 84,0 & $1976 \ldots \ldots \ldots \ldots$ & $25.884,0$ & $23.721,6$ \\
\hline $1926 \ldots \ldots \ldots \ldots$ & 81,0 & 80,2 & $1977 \ldots \ldots \ldots \ldots$ & $30.996,8$ & $29.107,9$ \\
\hline $1927 \ldots \ldots \ldots \ldots$ & 76,6 & 88,8 & $1978 \ldots \ldots \ldots \ldots$ & $32.242,4$ & $33.985,1$ \\
\hline $1928 \ldots \ldots \ldots \ldots$ & 89,4 & 95,6 & $1979 \ldots \ldots \ldots \ldots$. & $38.394,9$ & $37.842,8$ \\
\hline $1929 \ldots \ldots \ldots \ldots$ & 97,8 & 112,6 & $1980 \ldots \ldots \ldots \ldots$ & $43.935,4$ & $44.882,4$ \\
\hline $1930 \ldots \ldots \ldots \ldots$ & 100,0 & 100,0 & $1981 \ldots \ldots \ldots \ldots$ & $56.955,7$ & $52.460,8$ \\
\hline
\end{tabular}




\section{BIBLIOGRAFÍA}

Anuario de Bilbao, que comprende el historial de las sociedades anónimas de España (varios años), Bilbao, Banco de Vizcaya (más tarde, denominado Anuario Financiero de Bilbao).

Anuario(s) Financiero(s) y de Sociedades Anónimas de España (varios años), Madrid, Daniel Riu (después SOPEC).

BANCO DE BILBAO (1978): Renta nacional de España y su distribución provincial. Serie bomogénea, 1955-1975, Bilbao, Banco de Bilbao.

- (varios años), Renta nacional de España y su distribución provincial, Bilbao, Banco de Bilbao.

Betran Pérez, Concha (1994): «El fraude fiscal en la industria: España, 1913-1929. El impuesto de utilidades», Hacienda Pública Española.

CARRERAS, A. (1984): «La producción industrial española, 1842-1981: construcción de un índice anual», Revista de Historia Económica, núm. 1.

- (1985): «Gasto nacional bruto y formación de capital en España, 1849-1958: primer ensayo de estimación», en Martín ACENA, P. y PRAdos de la Escosura, L., (eds.), La Nueva Historia Económica en España, Madrid, Tecnos.

CATALÁN, J. (1995): La economia española y la segunda guerra mundial, Barcelona, Ariel.

Comin, F. (1988): Hacienda y economía en la España contemporánea (1800-1936), 2 vols., Madrid, Instituto de Estudios Fiscales.

-- (1996): Historia de la Hacienda pública, II, España (1808-1995), Barcelona, Crítica.

Duménil, G., y Lévy, D. (1993): The Economics of the Profit Rate. Competition, Crises and Historical Tendencies in Capitalism, Aldershot, Edward Elgar.

EChevarría, G., y HeRrero, J. L. (1989): «La evolución de la economía española durante el período 1940-1988 a partir de un indicador de la tasa de beneficio del sector industrial», Información Comercial Española, núm. 665.

Gomez Lopez, M. ${ }^{a}$ L.; Melis, F., y Truyols, M. A. (1994): «Las cuentas de las empresas industriales en las estadísticas tributarias», Economia Industrial, núm. 299.

Martinez Méndez, P. (1991): Los beneficios de la banca, 1970-1989, Madrid, Banco de España.

Ortega, M. (1994): «La Central de Balances del Banco de España: una fuente de información sobre las empresas no financieras españolas», Economía Industrial, núm. 299.

Prados, L. (1993): Spains's Gross Domestic Product, 1850-1990: A New Series, Madrid, Dirección General de Planificación, Ministerio de Economía y Hacienda, D-93002.

- (1995): Spain's Gross Domestic Product, 1850-1993: Quantitative Conjectures, Madrid, Universidad Carlos III.

Roldán, S., y García Delgado, J. L. (con la colaboración de Juan MuÑoz) (1973): La formación de la sociedad capitalista en España, 1914-1920, 2 vols., Madrid, Confederación Española de Cajas de Ahorro.

Román, Manuel (1972): Los límites del crecimiento económico en España, 1959-1967, Madrid, Ayuso. 
Sánchez Fernández de Valderrama, J. L. (1989): Normalización y planificación contable, Madrid, Ministerio de Economía y Hacienda.

Tafunell, X. (1989): «Asociación mercantil y Bolsa», en Carreras, A. (comp.), Estadísticas bistóricas de España. siglos XIX y XX, Madrid, Fundación Banco Exterior.

- (1996): Los beneficios empresariales en España (1880-1981): elaboración de una serie anual, Madrid, Fundación Empresa Pública, documento de trabajo 9601.

UnzueTA, A. de (1978): Régimen fiscal de la empresa, Barcelona, s. p. i.

URIEL, E. (1986): Enlace entre los sistemas de Contabilidad Nacional CNE-58 y CNE-70, Madrid, Instituto de Estudios Fiscales.

Zarnowitz, V. (1992): Business Cycles. Theory, History, Indicators and Forecasting, Nueva York, National Bureau of Economic Research. 